\title{
Connections of Some Auditory-Responsive Posterior Thalamic Nuclei Putatively Involved in Activation of the Hypothalamo- Pituitary-Adrenocortical Axis in Response to Audiogenic Stress in Rats: An Anterograde and Retrograde Tract Tracing Study Combined With Fos Expression
}

\author{
SERGE CAMPEAU* AND STANLEY J. WATSON, JR. \\ Mental Health Research Institute, The University of Michigan, Ann Arbor, \\ Michigan 48109-0720
}

\begin{abstract}
Prior studies in our laboratory demonstrated that part of the thalamus is necessary for activating the hypothalamo-pituitary-adrenocortical (HPA) axis in response to audiogenic stress in rats. The present studies were designed to determine how the auditory-responsive thalamic nuclei might activate the HPA axis. Both retrograde [Fluoro-Gold (FG)] and anterograde [Phasoleus vulgaris-leucoagglutinin (PHA-L) and biotinylated dextran amines (BDA)] tracers were employed to study the putative connectivity between the thalamus and the medial parvocellular region of the hypothalamic paraventricular nucleus (PAmp). In addition, rats receiving FG in the PAmp were subjected to audiogenic stress, and the distribution of both FG and the protein product of the immediate-early gene c-fos, Fos, were determined by double immunohistochemistry, to help assess putative functional links between the auditory-responsive thalamic nuclei and PAmp. The results of PAmp FG placement indicated retrogradely labeled cells in several areas, including the bed nucleus of the stria terminalis, hypothalamic regions, the supramammillary nucleus, some thalamic regions, and importantly, a few multisensory nuclei of the thalamus, including the parvicellular division of the subparafascicular and posterior intralaminar nuclei. Injections of the tracers PHA-L or BDA into these auditory-responsive posterior thalamic nuclei provided further evidence of projections to the PAmp. In addition, several forebrain areas were observed to receive moderate to heavy innervation. These areas included most of the regions described above, which, in turn, project to the PAmp. Because cells in the multisensory thalamic nuclei, hypothalamic, and forebrain areas were double labeled with FG and Fos, the results suggest that either direct projections from the thalamus to PAmp neurons, or indirect projections from the thalamus to stress-responsive forebrain areas projecting to the PAmp, might mediate activation of the HPA axis by audiogenic stress. J. Comp. Neurol. 423: 474-491, 2000. ๑ 2000 Wiley-Liss, Inc.
\end{abstract}

Indexing terms: subparafascicular; intralaminar; preoptic; hypothalamus; noise; immunohistochemistry

One of the defining characteristics of stress involves the secretion of glucocorticoids from the hypothalamopituitary-adrenocortical axis (HPA) (Levine and Ursin, 1991; Ursin and Olff, 1993; Akil and Morano, 1995; Toates, 1995; Akil and Morano, 1996; Yehuda, 1997). The release of glucocorticoids in response to stressful stimuli is, in most instances, ultimately controlled by neurons of
Grant sponsor: NIMH; Grant number: MH-42251; Grant sponsor: Medical Research Council of Canada.

*Correspondence to: Serge Campeau, Ph.D., the Department of Psychology, P.O. Box 345, University of Colorado, Boulder, CO 80309-0345. E-mail: campeaus@psych.colorado.edu

Received 2 July 1999; Revised 18 February 2000; Accepted 28 March 2000 
the medial parvocellular region of the paraventricular nucleus of the hypothalamus (PAmp), which contain corticotropin-releasing factors, such as corticotropinreleasing hormone $(\mathrm{CRH})$, arginine vasopressin (AVP), and others (Antoni, 1986; Swanson et al., 1988; Sawchenko, 1991). The release of corticotropin releasingfactors at the level of the external zone of the median eminence, in the portal blood system, initiates the production and release of anterior pituitary adrenocorticotropin hormone (ACTH) in the general circulation, which in turn induces the production and release of adrenal glucocorticoids (corticosterone in rats).

It has thus been postulated that the paraventricular nucleus of the hypothalamus provides the central "final common relay," ultimately involved in the release of glucocorticoids. However, there are very few instances in which the control of the HPA axis has been ascribed to a specific set of anatomical afferents to the PAmp. One of these provides hypophysiotropic afferents from the catecholaminergic cell groups of the nucleus of the solitary tract and ventrolateral medulla involved in HPA activation by an immune challenge (Li et al., 1996). Exactly how most other stressors control the activity of the HPA axis remains largely speculative (Cullinan et al., 1996; Herman et al., 1996; Sawchenko et al., 1996; Herman and Cullinan, 1997; Li and Sawchenko, 1998).

Recently, we observed that audiogenic stress elicits the release of corticosterone, which is associated with a distinct pattern of brain activity in rats, as evidenced by the induction of the immediate-early gene c-fos (Campeau and Watson, 1997). Exposure of rats to intense white noise (90 and $105 \mathrm{dBA}$ for 30 minutes) produced significant c-fos mRNA induction in a handful of forebrain areas (the ventrolateral septum, septohypothalamic nucleus, anteroventral and anteromedial divisions of the bed nucleus of the stria terminalis, lateral preoptic area, medial preoptic nucleus, and ventral dentate gyrus), compared with rats exposed to lower, nonstressful noise levels. Most of these audiogenic stress-responsive forebrain structures have direct projections to regions of the paraventricular hypothalamic nucleus (Tribollet and Dreifuss, 1981; Sawchenko and Swanson, 1983; Simerly and Swanson, 1988; Bittencourt et al., 1991; Cullinan et al., 1993, 1996; Larsen et al., 1994; Moga and Saper, 1994; Herman et al., 1996; Li and Sawchenko, 1998).

\begin{tabular}{|c|c|c|c|}
\hline \multicolumn{4}{|c|}{ Abbreviations } \\
\hline $3 \mathrm{v}$ & third ventricle & $\mathrm{MnPO}$ & median preoptic nucleus \\
\hline ac & anterior commissure & MPA & medial preoptic area \\
\hline aca & anterior part of the anterior commissure & MPO & medial preoptic nucleus \\
\hline AcbC & accumbens nucleus, core & $\mathrm{mp}$ & mammillary peduncle \\
\hline AcbSh & accumbens nucleus, shell & MS & medial septal nucleus \\
\hline $\mathrm{ACe}$ & central nucleus of the amygdala & $\mathrm{mt}$ & mammillothalamic tract \\
\hline ACo & anterior cortical amygdaloid nucleus & $\mathrm{mtg}$ & mammillotegmental tract \\
\hline $\mathrm{ADP}$ & anterodorsal preoptic nucleus & MTu & medial tuberal nucleus \\
\hline $\mathrm{AH}$ & anterior hypothalamic & opt & optic tract \\
\hline $\mathrm{Aq}$ & aqueduct of Sylvius & ox & optic chiasm \\
\hline ar & acoustic radiation & PAG & periaqueductal gray \\
\hline Arc & arcuate nucleus & PAap & paraventricular nucleus of the hypothalamus, anterior \\
\hline AStr & amygdalostriatal transition area & 1Аар & nucleus \\
\hline BL & basolateral nucleus of the amygdala & PAlm & paraventricular nucleus of the hypothalamus, lateral \\
\hline BLA & anterior basolateral nucleus of the amygdala & ГАाँ & magnocellular division \\
\hline $\mathrm{BLV}$ & ventral basolateral nucleus of the amygdala & PAmp & paraventricular nucleus of the hypothalamus, medial par- \\
\hline $\mathrm{BM}$ & basomedial nucleus of the amygdala & & vocellular division \\
\hline BMA & anterior basomedial nucleus of the amygdala & PBP & pigmented parabrachial nucleus \\
\hline BST & bed nucleus of the stria terminalis & $\mathrm{Pe}$ & periventricular nucleus of the hypothalamus \\
\hline BSTIA & bed nucleus of the stria terminalis, intraamygdaloid divi- & $\mathrm{PeF}$ & perifornical nucleus \\
\hline & sion & PIL & posterior intralaminar nucleus \\
\hline cp & cerebral peduncle & $\mathrm{PP}$ & peripeduncular nucleus \\
\hline $\mathrm{CPu}$ & caudate-putamen & $\mathrm{PH}$ & posterior hypothalamic area \\
\hline $\csc$ & & $\mathrm{pm}$ & principal mammillary tract \\
\hline $\begin{array}{l}\text { cst } \\
\text { DLG }\end{array}$ & $\begin{array}{l}\text { commissure of the stria terminalis } \\
\text { dorsal lateral geniculate nucleus }\end{array}$ & PoT & posterior thalamic nucleus \\
\hline $\begin{array}{l}\text { DLG } \\
\text { DMH }\end{array}$ & & PS & parastrial nucleus \\
\hline f & & PT & paratenial thalamic nucleus \\
\hline $\begin{array}{l}1 \\
\text { fr }\end{array}$ & $\begin{array}{l}\text { Iornix } \\
\text { fasciculus retroflexus }\end{array}$ & pv & periventricular fiber system \\
\hline GP & $\begin{array}{l}\text { Iascicuius retronexus } \\
\text { globus pallidus }\end{array}$ & PVA & anterior paraventricular thalamic nucleus \\
\hline HDB & nucleus of the horizontal limb of the diagonal band & PVP & posterior paraventricular thalamic nucleus \\
\hline ic & internal capsule & $\mathrm{RCh}$ & retrochiasmatic area \\
\hline IGL & intergeniculate leaf & $\mathrm{SC}$ & superior colliculus \\
\hline LA & lateral nucleus of the amygdala & $\mathrm{SCh}$ & suprachiasmatic nucleus \\
\hline $\mathrm{LH}$ & lateral hypothalamic area & SG & suprageniculate nucleus of the thalamus \\
\hline LSd & dorsal lateral septum & SI & substantia innominata \\
\hline $\mathrm{LSi}$ & intermediate lateral septum & sm & stria medullaris of thalamus \\
\hline $\mathrm{LSv}$ & ventral lateral septum & $\mathrm{SN}$ & substantia nigra \\
\hline LP & lateral posterior thalamic nucleus & SPF & subparafascicular nucleus \\
\hline LPO & lateral preoptic area & SPFPC & parvicellular division of the subparafascicular nucleus \\
\hline LV & lateral ventricle & st & stria terminalis \\
\hline $\mathrm{MeA}$ & medial nucleus of the amygdala & StHy & striohypothalamic nucleus \\
\hline $\mathrm{mfb}$ & medial forbrain bundle & SuM & supramammillary nucleus \\
\hline MGD & dorsal division of the medial geniculate nucleus & vaf & ventral amygdalofugal pathway \\
\hline MGM & medial division of the medial geniculate nucleus & VMH & ventromedial nucleus of the hypothalamus \\
\hline MGV & ventral division of the medial geniculate nucleus & VP & ventral pallidum \\
\hline $\mathrm{ml}$ & medial lemniscus & $\mathrm{ZI}$ & zona incerta \\
\hline
\end{tabular}


Interestingly, rats sustaining disruption (ibotenic acid lesions) of the entire auditory thalamus and of the adjacent multisensory lateral parvicellular division of the subparafascicular nucleus and posterior intralaminar nucleus, display a specific and complete blockade of audiogenic stress-induced corticosterone release, as well as a near complete abolition of c-fos mRNA induction in stress-responsive forebrain structures (Campeau et al., 1997). These results suggested that at least some of these auditory-responsive thalamic regions are part of a system ultimately providing excitatory input to the hypophysiotropic neurons of the paraventricular nucleus of the hypothalamus necessary for audiogenic stress-induced HPA axis activation.

The main goal of the present studies was to determine how the auditory-responsive thalamic nuclei might convey excitatory drive upon the hypophysiotropic neurons of the paraventricular nucleus of the hypothalamus. Both retrograde [Fluoro-Gold (FG)] and anterograde [Phasoleus vulgaris-leucoagglutinin (PHA-L) and biotinylated dextran amines (BDA)] tract-tracing procedures were employed to study putative connections between auditoryresponsive thalamic nuclei and PAmp. To complement these anatomical approaches, a combination of retrograde neuronal tracing from the PAmp with Fos immunocytochemistry in rats exposed to audiogenic stress was performed to assess putative functional afferent inputs to the PAmp during this type of challenge.

\section{MATERIALS AND METHODS Subjects}

Fifty-nine naive male albino Sprague-Dawley rats weighing 250-300 g (Charles River, Kingston, NY), were used. Rats were housed in groups of two in plastic cages $(20 \times 25 \times 50 \mathrm{~cm})$ and maintained on a 12-hour/12-hour light-dark cycle (lights on at 7:00 am) with water and food freely available. They were accustomed to the colony for at least 1 week before injections were made.

\section{Tracer injections}

Rats were anesthetized with sodium pentobarbital (Butler, $\mathrm{OH} ; 50 \mathrm{mg} / \mathrm{kg}$, i.p.). They were shaved and placed in a Kopf stereotaxic instrument fitted with blunt earbars. The skin overlying the skull was disinfected (with Betadine), an incision was made, and a small window $(2 \times 2 \mathrm{~mm})$ was drilled through the skull bone to allow penetration of glass capillaries (10-15 $\mu \mathrm{m}$ external tip diameter). Capillaries were backfilled with either a $2 \%$ solution of FG (Fluorochrome, Denver, CO) dissolved in $0.9 \% \mathrm{NaCl}$, a $2.5 \%$ solution of PHA-L, (\# L-1110, Vector, Burlingame, CA) dissolved in $10 \mathrm{mM}$ sodium phosphate buffer (PB; $\mathrm{pH} 8.0$ ), or 5\% BDA, 10,000 MW (Molecular Probes, Eugene, OR) dissolved in $0.1 \mathrm{M} \mathrm{PB}$ ( $\mathrm{pH}$ 7.4). Discrete FG deposits were made by iontophoresis in the PVN (1-1.5 $\mu \mathrm{A}, 7$ seconds on/off, 3-5 minutes) in 35 rats. Deposits of PHA-L $(\mathrm{n}=14)$ or BDA $(\mathrm{n}=10)$ were achieved by iontophoresis in the region of the thalamic posterior intralaminar nucleus and lateral parvicellular region of the subparafascicular nucleus ( $5 \mu \mathrm{A}, 7$ seconds on/off, 15 minutes). Following iontophoresis, the capillaries were left in place for 10 minutes before removal to minimize tracer leakage up the capillary tract. The scalp incision was closed with surgical stainless steel wound clips. Survival time ranged from 7 to 10 days. All procedures were approved by the Animal Care and Use
Committee of the University of Michigan and conformed to NIH guidelines involving vertebrate animals in research.

\section{Noise stress procedure}

Prior to perfusion, rats were transferred from the colony room to an adjacent room, in their home plastic cages, into an acoustically insulated box $(1.2 \times 1.0 \times 1.0 \mathrm{~m})$, in which they were subjected to 30 minutes of white noise at an intensity of $110 \mathrm{~dB}$ (A scale). They were returned to the colony room immediately after the end of loud noise stress. All rats were stressed between 7:00 am and 12:00 pm.

\section{Histology and immunocytochemistry}

Ninety to 105 minutes after the end of stress, rats were given an overdose of sodium pentobarbital $(1 \mathrm{ml})$ and perfused transcardially with ice-cold solutions, first with $50-100 \mathrm{ml}$ of $0.9 \% \mathrm{NaCl}$ containing $2.2 \% \mathrm{NaNO}_{2}$, followed by $400 \mathrm{ml}$ of $4 \%$ paraformaldehyde in $0.1 \mathrm{M} \mathrm{PB}$ (pH 7.4). Brains were then removed and postfixed in the same fixative for 1 hour at $4^{\circ} \mathrm{C}$, and then transferred and stored in $0.1 \mathrm{M}$ PB containing $10 \%$ sucrose at $4^{\circ} \mathrm{C}$, until sectioned (3-14 days later). Sectioning was performed in a Jung CM 1800 cryostat; six series of $35-\mu \mathrm{m}$ sections were collected into a cryoprotectant solution (30\% ethylene glycol and $30 \%$ sucrose in $0.05 \mathrm{M} \mathrm{PB}, \mathrm{pH} 7.2$ ) and kept at $-20^{\circ} \mathrm{C}$ until immunocytochemical processing.

All antisera used for immunocytochemical processing were diluted in a solution of $0.1 \mathrm{M}$ PB containing $0.25 \%$ carrageenan lambda and 0.5\% Triton X-100 (Sigma, St. Louis, MO). Detection of all antisera was carried out using the avidin-biotinylated enzyme complex method (Vectastain Elite ABC peroxidase kit, Vector). All incubations were carried out under gentle agitation at room temperature, unless otherwise specified. Sections from one series were first given six rinses in cold PB. They were then incubated for 20 minutes in a solution of $0.1 \mathrm{M}$ PB containing $0.3 \%$ hydrogen peroxide and given an additional six rinses in cold PB. Sections were incubated for 20 minutes each in avidin and biotin blocking solutions (1:5; Vector) in $0.1 \mathrm{M} \mathrm{PB}$, with one rinse in cold PB between the two incubations. Sections were then incubated in the immunocytochemical diluent for 1 hour and transferred into rabbit polyclonal antisera against either FG (1:50,000; developed in our laboratory), FOS (1:8,000; Santa Cruz Biotechnology, Santa Cruz, CA), CRH (1:16,000; a generous gift from Dr. W. Vale, The Salk Institute, San Diego, CA), or a goat polyclonal antiserum against PHA-L (1: 8,000; Vector) for $40-50$ hours at $4^{\circ} \mathrm{C}$, followed by six rinses in cold $\mathrm{PB}$.

Sections were then incubated in biotinylated goat antirabbit (1:1000; Vector) or rabbit anti-goat IgGs (1:1000) for 2 hours and the ABC complex for 2 hours, with six rinses in cold $\mathrm{PB}$ between incubations. A peroxidase reaction was performed for 8-12 minutes, which included 2.0 mg of the chromagen 3,3'-diaminobenzidene (DAB) tetrachloride (Sigma), and $8.3 \mu$ l of a $0.3 \%$ solution of hydrogen peroxide, which were added to $10 \mathrm{ml}$ of a solution of $0.1 \mathrm{M}$ sodium acetate buffer ( $\mathrm{pH}$ 7.6) and produced a brown reaction product. In some cases, especially those involving double labeling, the peroxidase solution was prepared with the addition of $0.25 \mathrm{~g}$ of nickel ammonium sulfate, which produced a dark blue reaction product. The double detection of FG and Fos, and that of PHA-L and CRH, was obtained in the same sections by sequentially following the steps described above, with Fos and $\mathrm{CRH}$ visualized 
with the DAB/nickel reaction and FG and PHA-L visualized with DAB. The differential cellular localization of Fos and FG (nuclear vs. cytoplasmic) helped in the identification of single- and double-labeled cells. CRH and PHA-L were not colocalized, and were thus easily discriminated.

Controls for cross-reactivity of the antisera, especially in the double-labeling experiments, consisted of processing additional sections with protocols identical to those described above without the addition of primary or secondary antibodies. Nonspecific labeling was not observed under these conditions. In addition, the staining pattern for each antigen was similar whether single or double labeling was performed.

Sections processed for the detection of FG, PHA-L, or BDA were mapped using a Zeiss Axioplan microscope equiped with a camera lucida attachement. Sections sequentially processed for the detection of Fos and FG, or PHA-L and CRH, were mapped using a computer-assisted camera lucida (Neurolucida System, MicroBrightField, Colchester, VT). In both cases Nissl-counterstained sections, from processed material after coverslip removal, were used to help delineate structural boundaries. The nomenclature employed is that of Paxinos and Watson (1998). Photomicrographs (Figs. 1, 3, and 4) were acquired digitally via MCID Software (St. Catherine, Ontario, Canada) with a color CCD camera (SONY DXC-970MD) fixed onto the microscope; they were then transferred to Adobe Photoshop (ver. 4.0), and contrast and brightness were adjusted to provide the best visual results.

\section{RESULTS}

\section{Fluoro-Gold retrograde labeling}

In eight cases of FG injections aimed at the PAmp, the injection sites were observed to encompass the PAmp, with variable areas of tracer diffusion around the medial parvocellular region. The injection sites in these cases are sketched in Figure 1A. The most notable difference in retrograde labeling was observed in the anterior bed nucleus of the stria terminalis. These differences appear to be attributable to the exact anterior-posterior level of FG deposit, with more anterior PAmp injections labeling more cells in the anterior BST. Figure 1B presents a darkfield photomicrograph of the injection site in the PAmp in case FG\#28. Thirteen additional cases had misplaced injections, or the tissue was unusable due to freezing artifacts. Fourteen cases had very large injections that did not provide useful information. Three of the eight cases with relatively limited FG spread from the PAmp (cases \#18, 21, and 32; see Fig. 1) were processed for double immunocytochemistry against FG and Fos protein, which was induced by subjecting the injected rats to 30 -minute audiogenic stress 90-105 minutes prior to perfusion. The three brains from stressed rats showed a very similar pattern of FG retrograde labeling, which is represented by the camera lucida drawings (from case FG\#32, at nine different levels of the forebrain) in Figure 2 (B1-B9).

At the rostral levels examined, the pattern of retrograde labeling matched those reported previously, with some variability in the number of labeled cells. Labeling was, for the most part, located ipsilateral to the side of injection; when present, contralateral labeling was scattered but in the same regions as those observed ipsilaterally. Very few labeled cells were observed in the ventrolateral septal nucleus (Fig. 2B1,B2); more numerous cells were
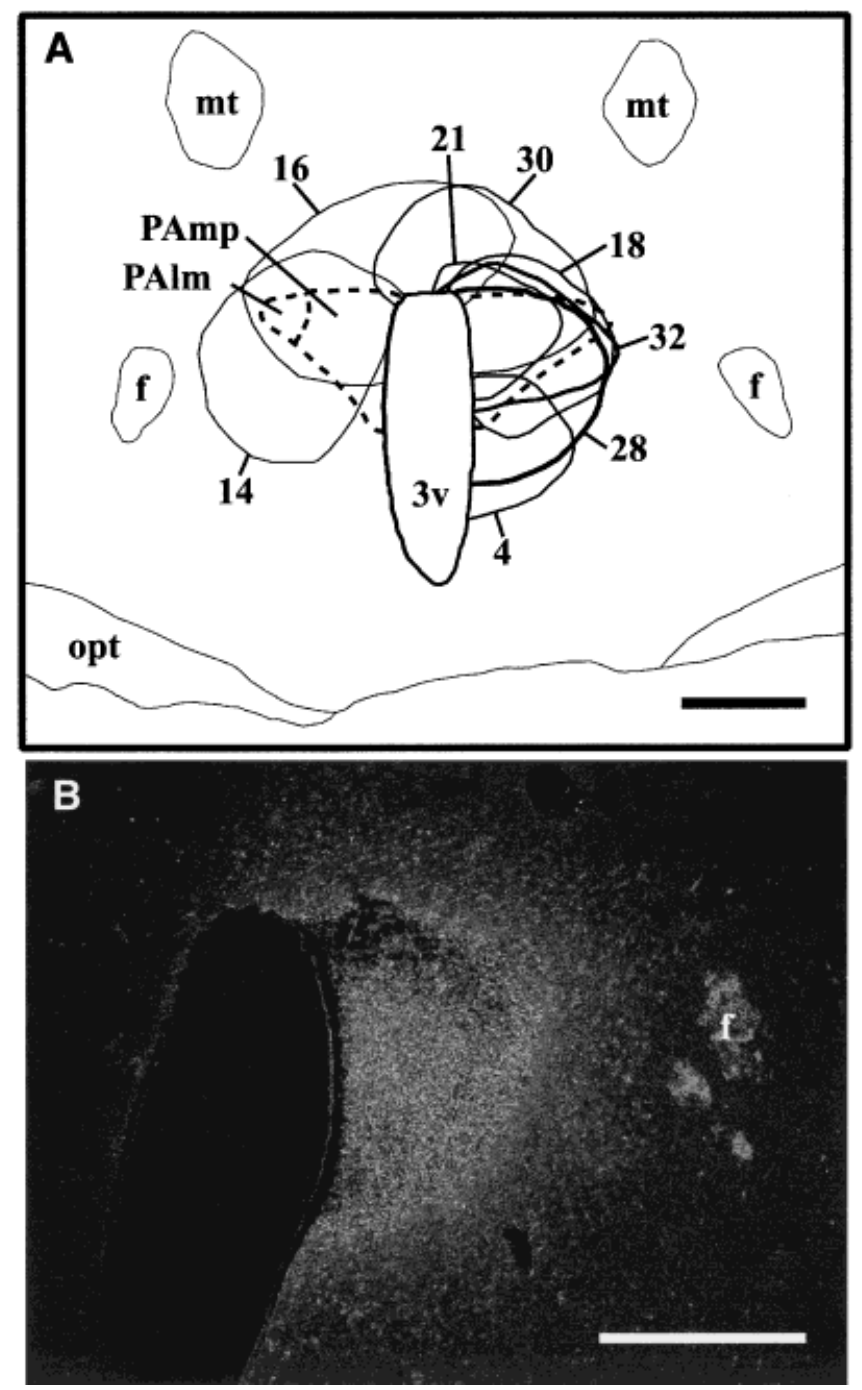

Fig. 1. A: Schematic representation of the extent of the FluoroGold injection sites in the region of the paraventricular nucleus of the hypothalamus. B: Darkfield photomicrograph of the injection site in case FG\#28. Scale bars $=500 \mu \mathrm{m}$.

labeled in this region upon injection placement centered on the border or adjacent to the PAmp. Several subdivisions of the bed nucleus of the stria terminalis also contained scattered retrogradely labeled neurons, most notably the anteromedial, anteroventromedial and posteromedial divisions (Fig. 2B1-B3), but this varied with the exact level of FG deposit. The preoptic area was one of the heaviest labeled regions, with the median preoptic nuclei, medial and lateral medial preoptic nuclei and medial preoptic area containing the most cells, the ventrolateral and ventromedial preoptic nuclei a moderate number of cells, and few cells in the lateral preoptic nucleus (Fig. 2B2-B3). The parastrial nucleus contained several retrogradely labeled cells as well (Fig. 2B2). At rostral levels of the hypothalamus, a few cells were observed in the striohypothalamic, supraoptic, and suprachiasmatic nuclei, with several retrogradely labeled neurons in the anterior parvocellular part of the hypothalamic paraventricular and periventricular nuclei (Fig. 2B3,B4). At the level of 
the injection site, the retrochiasmatic area contained several labeled cells, with additional cells in the anterior hypothalamic area (Fig. 2B3,B4). Numerous retrogradely labeled cells were observed in the ventromedial, and dorsomedial hypothalamic nuclei; labeling subsided quickly in the tuber cinereum, perifornical and lateral hypothalamic regions (Fig. 2B4,B5). At more caudal hypothalamic sites, the posterior hypothalamic area and supramammillary nucleus displayed several retrogradely labeled cells (Fig. 2B6).

Of the extrahypothalamic regions displaying retrogradely labeled cells, the anterodorsal and posterodorsal medial nuclei of the amygdala showed a few scattered cells, with one or two cells occasionally labeled in the medial aspect of the central nucleus of the amygdala (data not shown). Several thalamic areas also showed FG retrograde labeling. Of particular interest to the present study, some of the heaviest thalamic labeling was observed in the subparafascicular nucleus, including its lateral parvicellular division, and the anterior paraventricular nucleus (Fig. 2B7,B8). Several cells were also observed in the medial aspect of the posterior intralaminar nucleus (Fig. 2B7-B9). Examples of retrograde labeling in the subparafascicular and posterior intralaminar nuclei, which are well-known auditory-responsive areas, are depicted in Figure $3 \mathrm{D}$ and E. The anteromedial zona incerta (Fig. 2B7) and periaqueductal gray area (data not shown) also had a moderate number of retrogradely labeled cells. A few labeled cells were scattered in the superior colliculus, immediately above the commissure of the superior colliculus (data not shown), and laterally, in the intergeniculate leaflet (data not shown). Sections were not processed at levels caudal to the auditory thalamus.

\section{Fos protein immunocytochemistry}

The Fos-like immunoreactivity induced by audiogenic stress in the three brains processed for double immunocytochemistry was extensive throughout several structures and comparable in different rats; it is represented by the camera lucida drawings (from case FG\#32, at nine different levels of the forebrain) in Figure 2A1-A9. Under conditions in which similarly treated rats are simply placed in acoustic enclosures within their home cages at ambient noise levels ( $~ 55$ dBA SPL), virtually no Fos-like positive neurons are detected, except for some cells in the suprachiasmatic nucleus, the anteroventral and anterodorsal thalamic nuclei, and the lateral geniculate nuclei (data not shown). The forebrain regions displaying high levels of Fos-like immunoreactivity included the cingulate cortex and more caudally the retrosplenial cortex (not shown), the ventral lateral septum (Fig. 2A1,A2), the anteromedial bed nucleus of the stria terminalis (Fig. 2A1), the dorsal endopiriform and piriform cortex, and the adjacent olfactory tubercule (not shown). Levels rostral to the septum were not processed in this study. More moderate numbers of Fos-positive neurons were observed in the medial aspect of the caudate-putamen, immediately against the lateral ventricle (Fig. 2A1,A2), the horizontal nucleus of the diagonal band (Fig. 2A1,A2), the ventral endopiriform nucleus, and the interstitial nuclei of the anterior commissure (not shown). Scattered Fos-like positive neurons were also present in the dorsal striatum and somatosensory cortex, almost exclusively located in deep layers at more caudal levels (not shown).

At more posterior levels, Fos-like immunoreactive neurons were numerous in several preoptic areas, including the median and medial preoptic nuclei and medial preoptic area, parastrial nucleus, anterior parvocellular paraventricular hypothalamic nucleus, and anterior paraventricular thalamic nucleus (Fig. 2A2,A3). The anterior hypothalamic area contained several Fos-like positive cells (Fig. 2A4). Regions with moderate collections of Foslike positive neurons were the lateral preoptic area, the lateral hypothalamus, the periventricular hypothalamic nucleus, the medial zona incerta, the ventromedial nucleus of the hypothalamus, the tuber cinereum area (Fig. 2A3-A5), and the anterodorsal medial and anterior cortical nuclei of the amygdala (not shown). The dorsal thalamus also contained moderate to high numbers of Fos-like positive cells, especially from a "ring" made of the paracentral thalamic nucleus, closing onto the anterior paraventricular thalamic nucleus dorsally and medially (not shown). Scattered Fos-like positive cells were also observed in the anterior basomedial complex of the amygdala (not shown).

At the caudal levels examined, large numbers of Foslike positive cells were labeled in the dorsomedial nucleus of the hypothalamus, the posterior hypothalamus, the subparafascicular nucleus, and the supramammillary nucleus (Fig. 2A5,A6). Relatively high numbers of Fos-like positive neurons were also observed in the posterior paraventricular and precommissural nuclei of the thalamus (not shown). A moderate collection of Fos-positive neurons were also observed from the arcuate nucleus, the lateral posterior thalamic nucleus, the suprageniculate nucleus, and the medial division of the medial geniculate nucleus (Fig. 2A5-A9). Increasing numbers of Fos-positive cells were observed in the ventral and (more so) the dorsal divisions of the medial geniculate nucleus in a rostrocaudal direction (not shown). Interestingly, and relevant to the present study, the parvicellular zone of the subparafascicular nucleus and the posterior intralaminar nucleus also displayed moderate numbers of Fos-positive cells at rostral levels (Fig. 2A7-A9). Additional moderate numbers of Fos-like positive neurons in the periaqueductal gray, the ventral lateral geniculate nucleus and intergeniculate leaflet, and the deep layers of the superior colliculus were observed (not shown). Scattered Fos-like positive cells in the ventral tegmental area and posterior dorsal division of the medial geniculate nucleus could be observed (Fig. 2A9). Sections beyond the posterior level of the medial geniculate nucleus $(6.0 \mathrm{~mm}$ posterior to Bregma) were not processed.

\section{Fluoro-Gold and Fos double immunocytochemistry}

In general, Fos protein was observed in all areas where FG was retrogradely transported. Importantly, however, only a relatively small number of regions was observed with detectable and consistent double-labeled FG/Fos cells. The double-labeled cells in the three brains processed for double immunocytochemistry was comparable in the different rats and is represented by the camera lucida drawings (from case FG\#32, at nine different levels of the forebrain) in Figure 2C1-C9. In the present description, high numbers of double-labeled cells is indicated by greater than 10 cells, $5-10$ cells indicate moderate numbers, and less than 5 cells indicate a small number of double-labeled cells per section and area observed. Rostral regions containing high numbers of double-labeled cells included the median preoptic nucleus, the parastrial nu- 


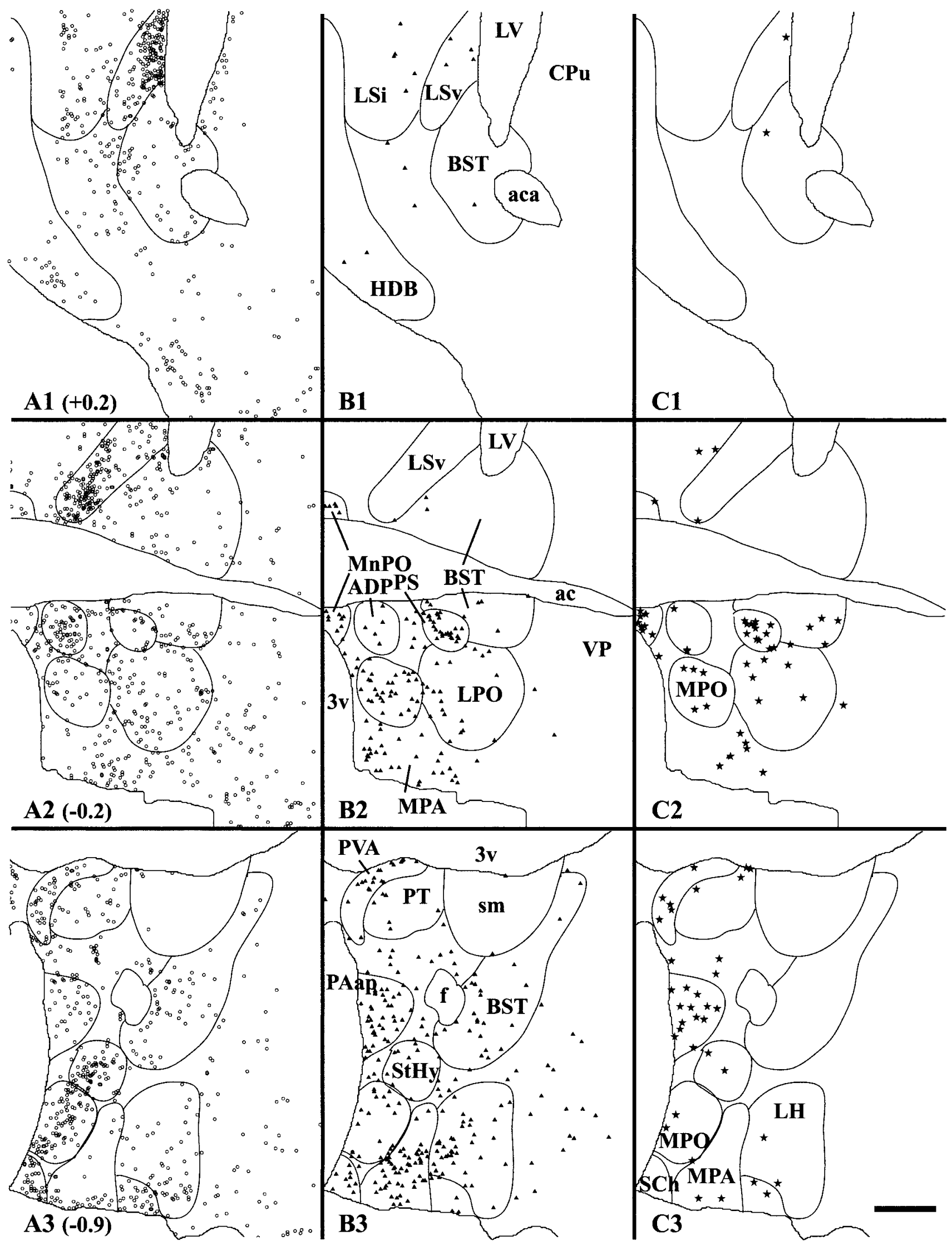

Fig. 2. Camera lucida drawings of the localization of Fos-like positive neurons (open circles, A1-A9) induced 90-105 minutes following 30-minute audiogenic stress, Fluoro-Gold retrogradely labeled neurons following iontophoretic deposit in the region of the medial parvocellular division of the paraventricular nucleus of the hypothalamus (filled triangles, B1-B9), and neurons labeled with both Fos and Fluorogold (filled stars, C1-C9), at nine different levels of the neuraxis (1-9). Scale bar $=500 \mu \mathrm{m}$ (applies to all panels). 


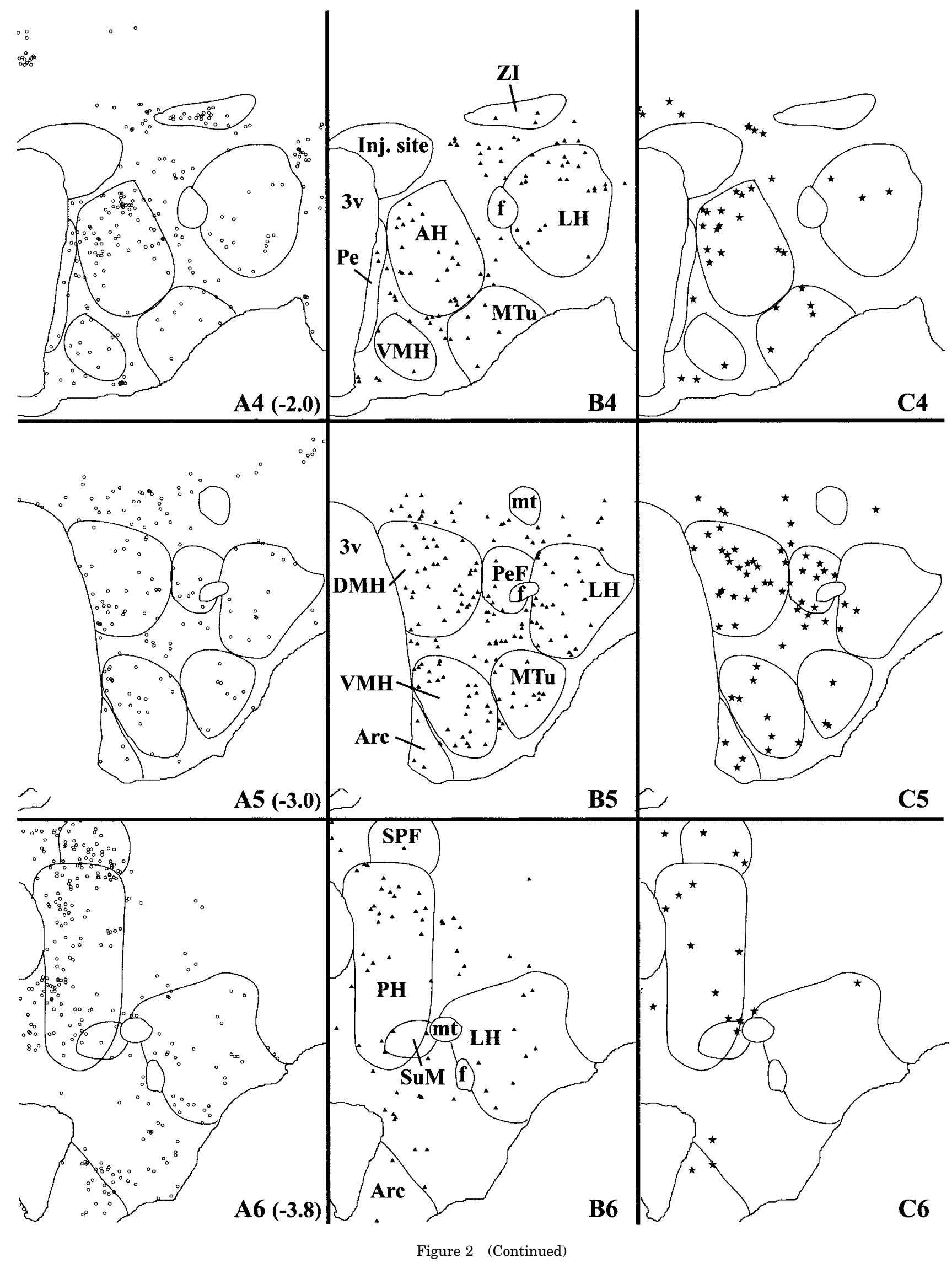




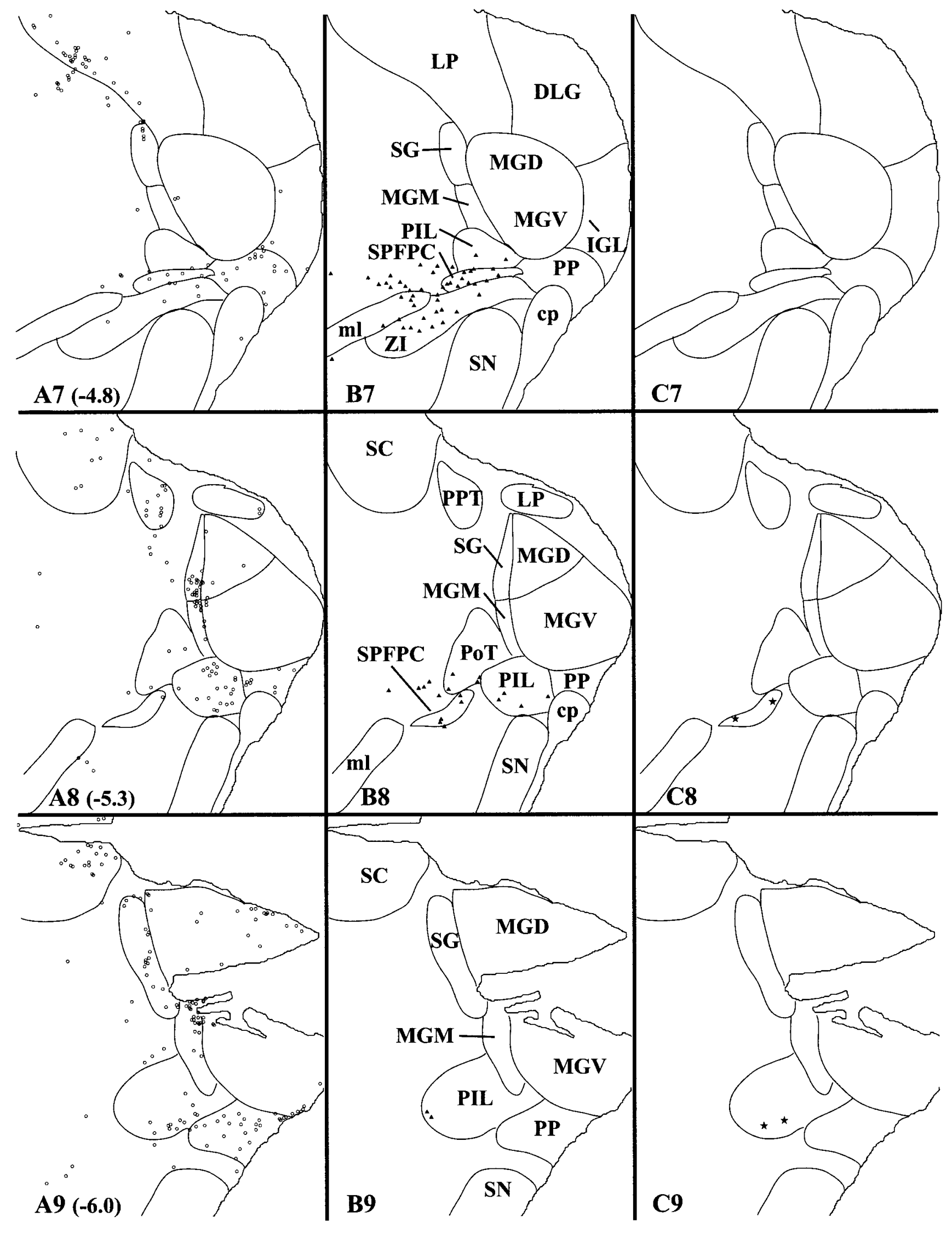

Figure 2 (Continued) 


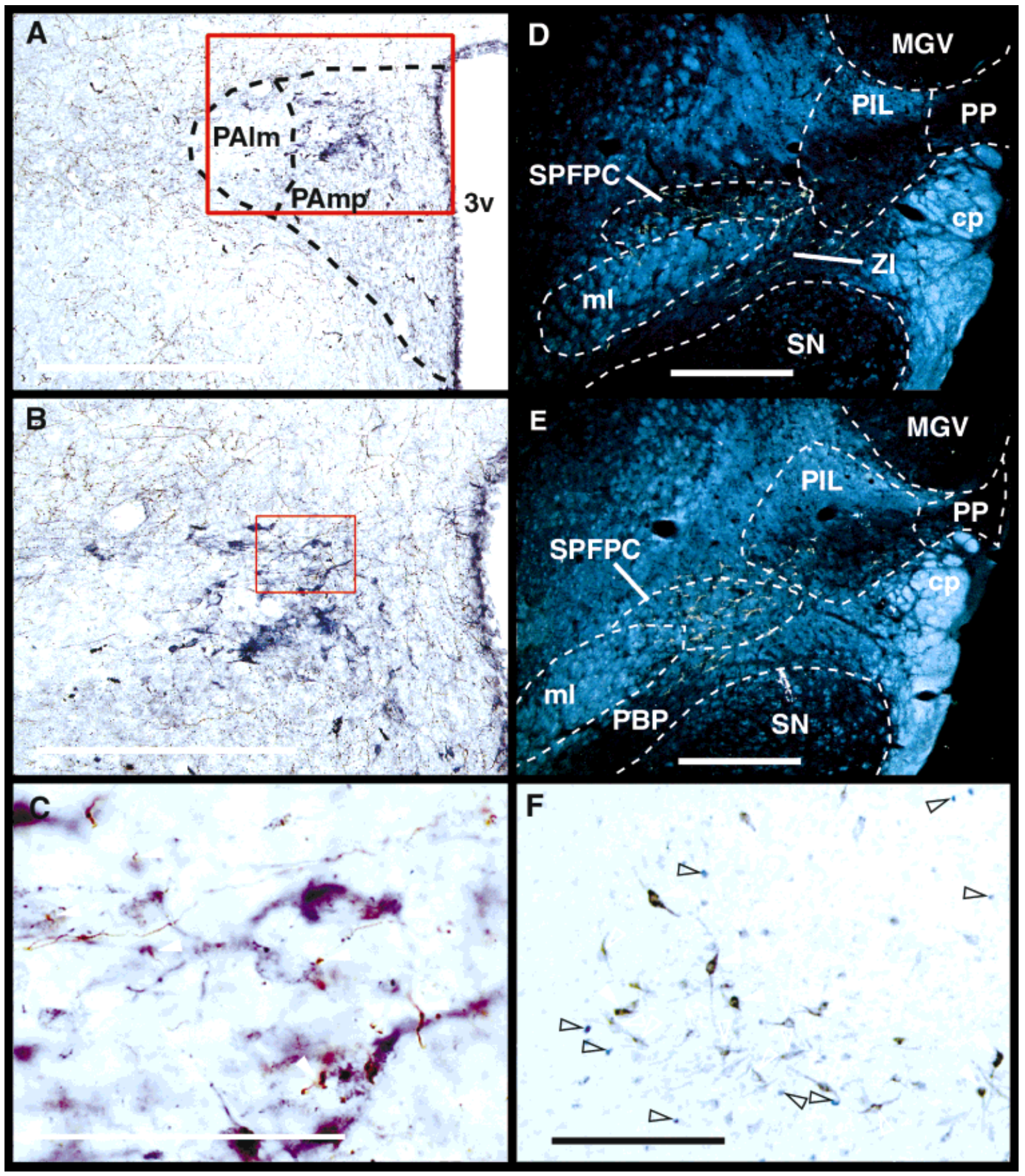

Fig. 3. A: Brightfield photomicrograph illustrating the location of PHA-L-labeled fibers and putative terminals (brown) in close proximity to corticotropin-releasing factor-positive cells (blue). The red square indicates the approximate level of the photomicrograph in B. B: Higher magnification of the brightfield photomicrograph presented in A showing several CRH-ir neurons in close proximity to PHA-L fibers and terminals. Note the absence of PHA-L fibers/terminals in the magnocellular (PAlm) division of the paraventricular nucleus of the hypothalamus. The red square indicates the approximate level of the photomicrograph in C. C: Higher magnification of the brightfield photomicrograph presented in B showing several CRH-like immunoreactive neurons in close proximity to PHA-L fibers/terminals (white arrowheads). Note that several of the PHA-L terminals show boutonlike structures. D: Darkfield photomicrograph depicting the localization of Fluoro-Gold retrogradely labeled cells (yellow) in the zona incerta (ZI), subparafascicular nucleus (SPFPC), and posterior intralaminar nucleus (PIL). E: Same as D at a more posterior level. F: Brightfield photomicrograph depicting the results of double immunohistochemistry against Fluoro-Gold (white arrowheads) and Fos (black arrowheads), with double-labeled neurons (filled white arrowheads) in the region of the bed nucleus of the stria terminalis at the level of the posterior aspect of the anterior commissure. Scale bars $=$ $500 \mu \mathrm{m}$ in A,D,E; $300 \mu \mathrm{m}$ in B; $50 \mu \mathrm{m}$ in $\mathrm{C} ; 200 \mu \mathrm{m}$ in $\mathrm{F}$. 
cleus, and the anterior parvocellular paraventricular hypothalamic nucleus (Fig. 2C2,C3).

Moderate numbers of double-labeled cells were observed in the medial preoptic nucleus, medial preoptic area, lateral preoptic nucleus, anteroventral bed nucleus of the stria terminalis, and anterior paraventricular thalamic nucleus (Fig. 2C2,C3). Small numbers of double-labeled neurons were observed in the striohypothalamic nucleus (Fig. 2C3). Examples of double-labeled neurons are depicted in Figure 3F. Near the injection site, high numbers of cells were double labeled in the anterior hypothalamic area (Fig. 2C4). At more posterior levels, high numbers of double-labeled neurons were observed in the dorsomedial nucleus of the hypothalamus (Fig. 2C5). Moderate numbers of double-labeled neurons were observed in the perifornical area, the ventromedial hypothalamic nucleus, and the posterior hypothalamus (Fig. 2C5,C6). Small numbers of double-labeled cells were detected in the lateral hypothalamus and arcuate nucleus (Fig. 2C4-C6). At the more posterior levels observed, small numbers of double-labeled cells were observed in the supramammillary nucleus, the subparafascicular nucleus (Fig. 2C6-C9), and the periaqueductal gray (not shown). Interestingly, small numbers of double-labeled cells were also detected in the auditoryresponsive parvicellular division of the supbparafascicular nucleus and the posterior intralaminar nucleus (Fig. 2C7-C9).

\section{PHA-L/BDA anterograde labeling}

As described above, the FG deposits were seldom limited within the boundaries of the CRH-containing PAmp neurons. It was thus possible that the retrogradely labeled cells observed in the auditory-responsive parvicellular region of the subparafascicular nucleus (SPFPC) and posterior intralaminar nucleus (PIL) might have been produced by extra-PAmp FG diffusion. To examine this possibility, additional rats were injected with the anterograde tracers PHA-L or BDA in the region of the subparafascicular and posterior intralaminar nuclei. Five of the 14 PHA-L cases showed PHA-L uptake in the region of the subparafascicular and posterior intralaminar nuclei. One of the $10 \mathrm{BDA}$ cases showed BDA uptake specifically in the subparafascicular and posterior intralaminar nuclei. The injection sites in these cases are sketched in Figure 4 . The other PHA-L and BDA cases displayed uptake in areas surrounding, but mostly excluding, the subparafascicular and posterior intralaminar nuclei.

The diffusion of BDA from the injection sites appeared more limited and allowed for a clearer observation of the area of neuronal uptake. Cases with injections containing PHA-L or BDA uptake in the subparafascicular and posterior intralaminar nuclei showed a similar pattern of anterograde labeling and are represented by the camera lucida drawings (from case BDA\#2, at 16 different levels of the forebrain) in Figure 5. By far the heaviest concentration of fibers and putative terminals was observed ipsilateral to the injection site. Several fibers were observed to course caudally from the injection site, but these caudal projections were not followed (Fig. 5A). At the level of the injection site, moderate numbers of fibers and putative terminals were seen dorsally into the medial division of the medial geniculate body and suprageniculate nucleus (Fig. 5B,C). Some fibers were also seen coursing through the commissure of the superior colliculus, giving rise to an apparent contralateral innervation of the deep layers of
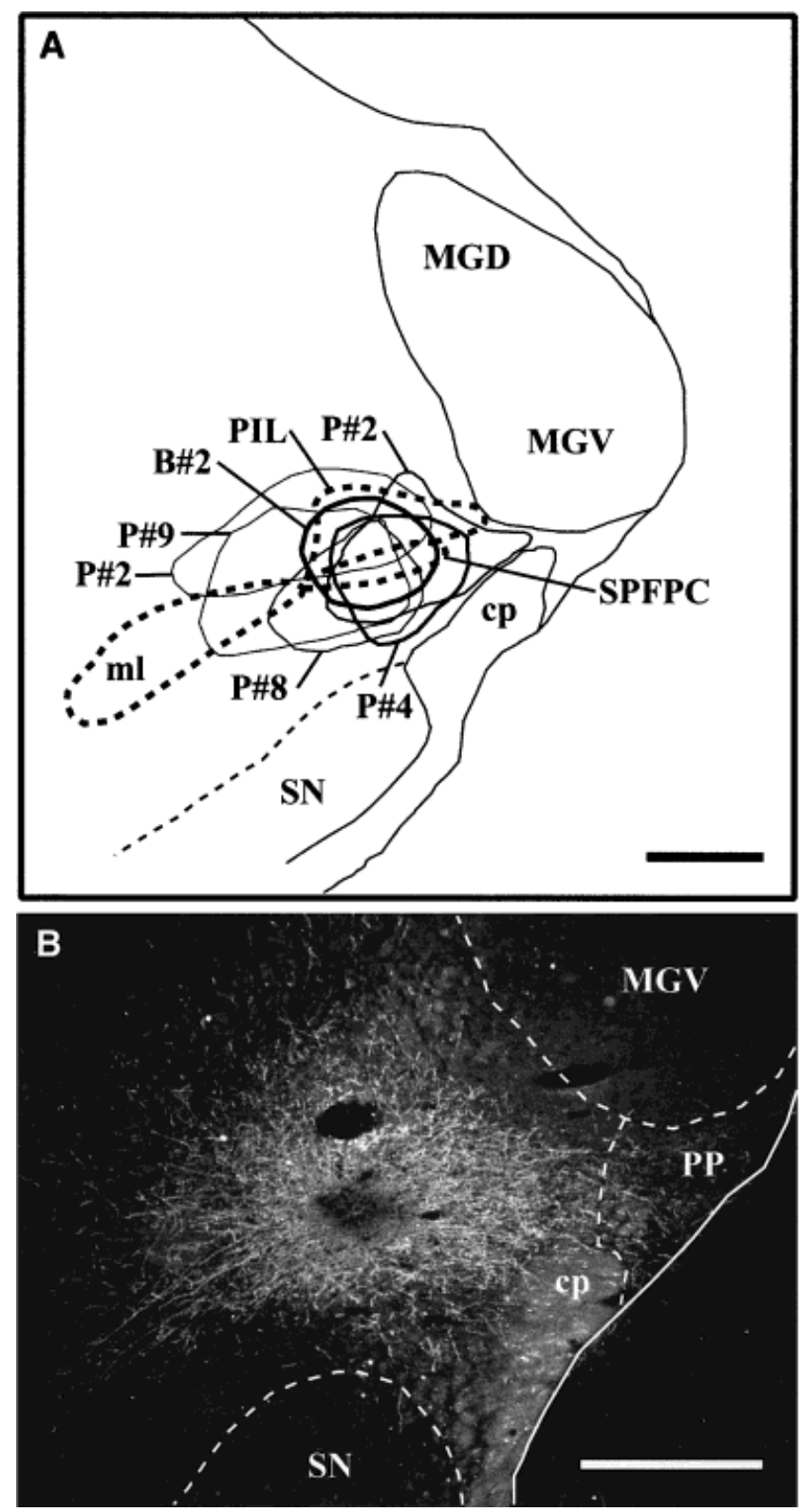

Fig. 4. A: Schematic representation of the extent of the PHA-L or BDA injection sites in the region of the medial auditory thalamus. B: Darkfield photomicrograph of the injection site in case BDA\#2, described in the text and displayed in Figure 5. Scale bars $=500 \mu \mathrm{m}$.

the superior colliculus and dorsal and lateral periaqueductal gray (Fig. 5A-D).

One major fiber tract arising from the injection site coursed lateromedially through an area dorsal to the medial lemniscus, to join the periventricular fiber system (Fig. 5D-F). At least some of these fibers appeared to contribute to the heavy innervation of several hypothalamic nuclei, including the ventral part of the ventromedial nucleus, dorsomedial nucleus, tuber cinereum area, and dorsal and anterior hypothalamic areas (Fig. 5H-L). Fewer putative terminals were observed in the lateral hypothalamic area (Fig. 5I-L). The possibility of direct 


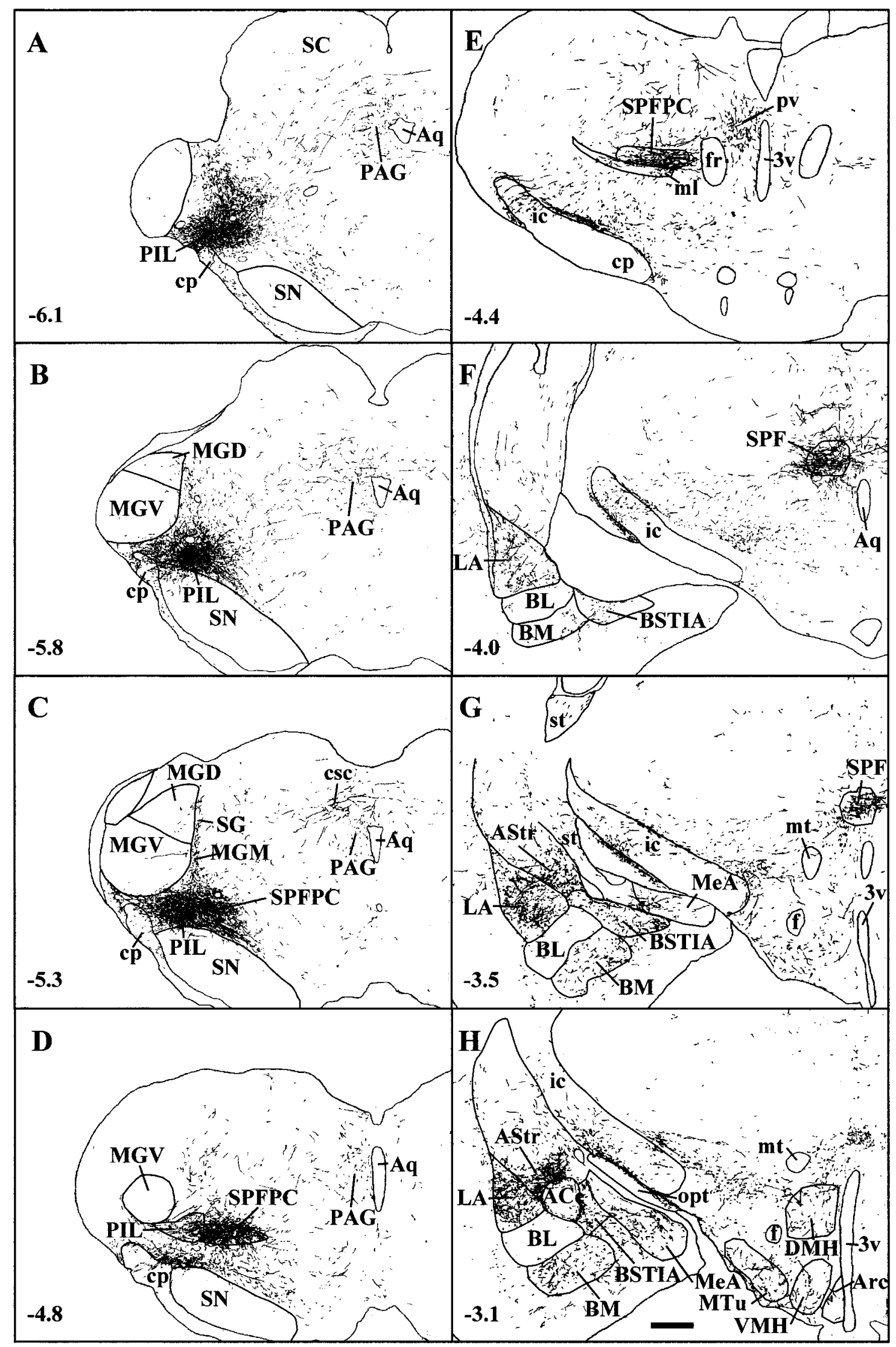

Fig. 5. Camera lucida drawings of BDA-immunoreactive cells, fibers, and terminals labeled after iontophoretic injection in the region of the parvicellular division of the subparafascicular nucleus and posterior intralaminar nucleus of the thalamus (B and C), at 16 different levels of the neuraxis (A-P). Scale bars $=500 \mu \mathrm{m}$ in H,P (applies to all panels). 


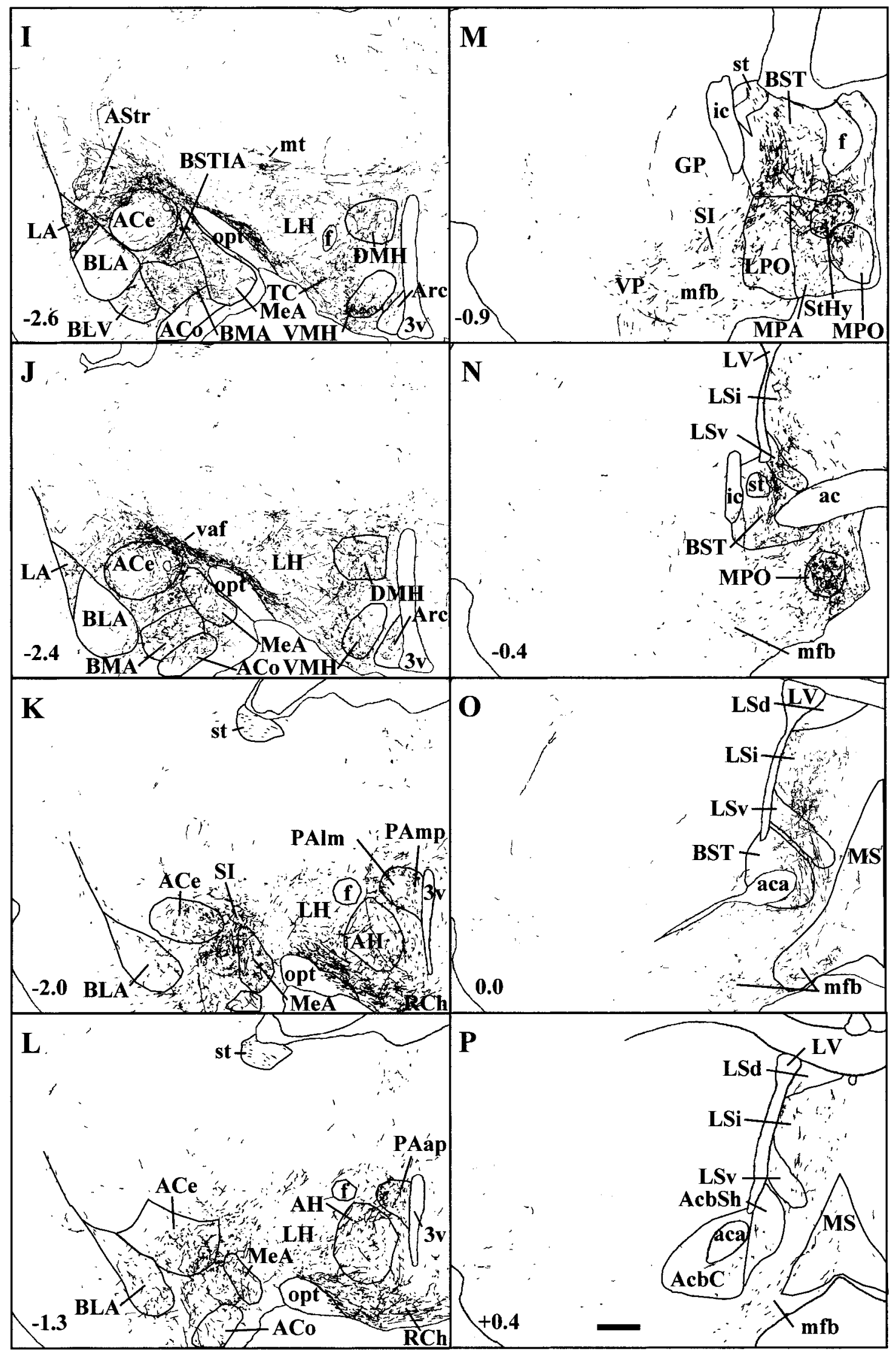

Figure 5 (Continued) 
projections from the parvicellular division of the subparafascicular and posterior intralaminar nuclei to the medial parvocellular nucleus of the paraventricular hypothalamic nucleus was substantiated by the observation of several fibers and putative terminals in this subdivision (Fig. 5K). However, the magnocellular component of the paraventricular nucleus was nearly devoid of putative terminals (Fig. 5K). Figure 3A-C shows brightfield photomicrographs from sections processed for double immunocytochemistry against PHA-L and $\mathrm{CRH}$ peptide at the level of the PAmp in case PHA-L\#2, showing that PHA-L fibers and putative terminals from the subparafascicular and posterior intralaminar nuclei innervate $\mathrm{CRH}$-like immunoreactive neurons of the PAmp. Several fibers and putative terminals were also labeled in the periventricular nucleus of the hypothalamus (Fig. 5K-L).

The other major fiber tracts originating from the injection site joined the cerebral peduncle and internal capsule to course rostrally to many additional areas of the forebrain. Some of these fibers probably provided putative terminals observed in the amygdaloid complex (the lateral nucleus, the bed nucleus of the stria terminalis intraamygdaloid division, the anterior and posterior basomedial nucleus, the anterodorsal medial nucleus, the medial division of the central nucleus, and the amygdalostriatal transition area; see Fig. $5 \mathrm{~F}-\mathrm{L}$ ), as well as the perirhinal and temporal cortex (not shown). Fewer fibers and putative terminals were seen in the anterior central nucleus of the amygdala and the substantia innominata (Fig. 5K-L). Some of these innervations were observed bilaterally, probably via crossing at the level of the supraoptic decussation. Putative terminals could also be seen in the retrochiasmatic area (Fig. 5K-L). At the level of the bed nucleus of the stria terminalis, a dense plexus of innervation was observed in several lateral subdivisions (Fig. 5M,N); this innervation appeared more moderate in medial divisions, including the anterior medioventral division (Fig. 5N,O). Several preoptic regions were innervated by auditory-responsive posterior thalamic neurons; the medial preoptic area and the lateral part of the medial preoptic nucleus received several fibers and putative terminals (Fig. 5M,N). Scattered innervation of the lateral preoptic area was also observed. The striohypothalamic nucleus was also observed to receive a large number of putative terminals. The lateral septum received a relatively moderate innervation, particularly in the ventrolateral and intermediate subnuclei (Fig. 5N,O). Some fibers and putative terminals were also seen in the horizontal limb of the diagonal band (Fig. 5O,P). Sections rostral to $0.40 \mathrm{~mm}$ from Bregma were not processed.

The pattern of anterograde labeling after PHA-L/BDA injections in the lateral subparafascicular nucleus and posterior intralaminar nucleus was relatively specific compared with some of the injections that missed these areas and therefore served as good control injections. For instance, upon tracer uptake mostly limited to the lateral aspect of the zona incerta at anterior levels, labeling was very light and only observed in the central nucleus of the amygdala, with little, if any, projections to other amygdaloid areas (not shown). Very few fibers or putative terminals could be observed in the posteromedial aspects of the bed nucleus of the stria terminalis or the preoptic area; no label could be consistently detected in the hypothalamus or septum. Injection of tracer in the deep mesencephalic nucleus gave a pattern of labeling similar to that observed with zona incerta injections (not shown). Tracer uptake dorsal to the lateral subparafascicular and posterior intralaminar nuclei, in the region of the triangular posterior thalamic and limitans nuclei, produced the heaviest labeling in the medial aspect of the central and anterior basomedial nuclei of the amygdala and the lateral division of the bed nucleus of the stria terminalis (not shown). Little, if any, labeling could be observed in other amygdaloid, hypothalamic, septal, or cortical regions.

\section{DISCUSSION}

The results of the present studies point to neuronal afferent candidates involved in activation of the medial parvocellular neurons of the paraventricular nucleus of the hypothalamus, ultimately involved in audiogenic stress-induced release of glucocorticoids, in rats. The retrograde tract-tracing results obtained following discrete Fluoro-Gold deposits in the region of the paraventricular nucleus of the hypothalamus confirmed prior findings of the collection of neural afferents innervating hypophysiotropic paraventricular neurons and extended this complement to some auditory-responsive posterior thalamic nuclei, more specifically from neurons of the parvicellular division of the subparafascicular nucleus and posterior intralaminar nucleus. Because it is very difficult to limit tracer injections to a given cell type, or even within the boundaries of the hypothalamic medial parvocellular division, it was also important to demonstrate that these posterior thalamic areas innervate the $\mathrm{CRH}$-containing neurons of the paraventricular hypothalamic nucleus, and not only regions adjacent to these neurons. The anterograde tract-tracing results from discrete Phasoleus vulgaris leucoagglutinin or biotinylated dextran amine deposits in the region of the parvicellular division of the subparafascicular and posterior intralaminar nuclei indicated that neurons within these regions indeed provide several fibers and putative terminals to CRH-like immunoreactive neurons of the paraventricular nucleus of the hypothalamus.

In addition, these auditory-responsive thalamic neurons were observed to provide innervation to several hypothalamic and forebrain areas that were retrogradely labeled after FG injections in the paraventricular nucleus of the hypothalamus. Neurons in some of these areas, including the parastrial nucleus, anteroventral bed nucleus of the stria terminalis, median, medial, and lateral preoptic nucleus, medial preoptic area, dorsomedial hypothalamic nucleus, anterior and posterior hypothalamic areas, perifornical nucleus, and supramammillary nucleus were double labeled with the Fos and FG antibodies after FG injections in the region of the paraventricular hypothalamic nucleus. These areas thus provide candidate functional afferents through which audiogenic stress-related information might control the activity of hypophysiotropic paraventricular neurons and the HPA axis.

\section{Relationship to previous tract-tracing studies of the paraventricular nucleus of the hypothalamus}

The results of tract-tracing studies after injections of a variety of retrograde tracers in the region of the paraventricular nucleus of the hypothalamus in rats have been relatively consistent (Silverman et al., 1981; Tribollet and 
Dreifuss, 1981; Sawchenko and Swanson, 1982, 1983; Cullinan et al., 1993, 1996; Roland and Sawchenko, 1993; Larsen et al., 1994; Moga and Saper, 1994; Larsen and Mikkelsen, 1995) and will not be reviewed in detail here. In general however, our findings following FG tracer injections in the region of the paraventricular nucleus agree well with prior results of PAmp afferents from many diencephalic and telencephalic areas including most hypothalamic regions and various subnuclei of the bed nucleus of the stria terminalis.

As with several prior reports, our results were consistent with the view that the lateral septum, the amygdala, and the ventral subicular region of the hippocampus do not provide a rich innervation to the $\mathrm{CRH}$-containing medial parvocellular division of the paraventricular hypothalamic nucleus (Sawchenko and Swanson, 1983; Moga and Saper, 1994; Cullinan et al., 1996; Marcilhac and Siaud, 1997; Cheung et al., 1998; Prewitt and Herman, 1998). Indeed, based on anterograde tracing studies, these regions have been shown to project mainly to the perinuclear border of the parvocellular paraventricular nucleus, or to the autonomic portions of the parvocellular division without contributing significantly to the innervation of the CRH-containing PAmp nuclear zone (Sawchenko and Swanson, 1983; Oldfield and Silverman, 1985; Grove, 1988; Gray et al., 1989; Kohler, 1990; Staiger and Wouterlood, 1990; Canteras and Swanson, 1992; Cullinan et al., 1993; Canteras et al., 1995). The fact that we observed few cells retrogradely labeled in these areas following our injections suggests that the FG deposits in the cases presented in this study were concentrated within the nuclear zone of the PAmp.

The thalamic fields retrogradely labeled after FG injection in the PAmp were also similar to prior descriptions, especially from the anterior paraventricular thalamic nucleus, the anteromedial zona incerta, and the periaqueductal gray (Silverman et al., 1981; Sawchenko and Swanson, 1983; Levin et al., 1987; Cheung et al., 1998; Li and Sawchenko, 1998). As described for the forebrain projections above, these thalamic nuclei were shown to provide anterograde projections to the PAmp region (Cameron et al., 1995; Moga et al., 1995; Wagner et al., 1995; Floyd et al., 1996). The sparse collection of labeled cells from the intergeniculate leaf division of the lateral geniculate nucleus observed in the present study also agrees with the recent findings of projections from this zone to the periventricular hypothalamic nucleus, with fewer projections to the PAmp proper (Horvath, 1998). Another very small subset of neurons was nearly invariably labeled in the deep layers of the superior colliculus, which has not been reported previously. Evidence from previous studies of anterograde projections to the PAmp could not be ascertained from the superior colliculus.

Finally, in all the cases displaying FG deposit in the PAmp, a reproducible number of cells along the extent (medial and lateral) of the parvicellular division of the subparafascicular nucleus and medial posterior intralaminar nucleus were labeled. This collection of cells probably comprises the population of neurons mentioned by Sawchenko and coworkers (1996), with notable differences: first, retrograde labeling in the peripeduncular nucleus was not consistently observed in the present study; and second, Sawchenko and coworkers did not mention labeling in the subparafascicular nucleus. A more detailed evaluation of these apparent discrepancies is difficult be- cause of the scarcity of data presented (Sawchenko et al., 1996) and should await additional demonstrations. Nevertheless, deposits of the anterograde tracers PHA-L or $\mathrm{BDA}$ in the lateral parvicellular division of the subparafascicular nucleus and the posterior intralaminar nucleus provided, to our knowledge, the first detailed demonstration of projections from these thalamic subdivisions to the CRH-containing neurons of the medial parvocellular division of the paraventricular nucleus of the hypothalamus. Because the anterograde tracers were invariably taken up by cells of both the parvicellular subparafascicular and posterior intralaminar nuclei simultaneously, it cannot be ascertained whether one or the other region projects more specifically or heavily to the PAmp. These findings, however, strongly suggest that one or both of these posterior thalamic regions provide direct afferent innervation to the hypophysiotropic neurons of the paraventricular nucleus of the hypothalamus in the rat.

\section{Additional projections from the subparafascicular and posterior intralaminar nuclei}

Our study of the projection fields of the parvicellular division of the subparafascicular nucleus and posterior intralaminar nucleus yielded results that were much broader than most previously published work. Prior studies have focused mostly on connections from these thalamic areas to the amygdaloid complex and ventral striatum (Veening, 1978; Ottersen and Ben-Ari, 1979; Ottersen, 1981; Turner and Herkenham, 1981; LeDoux et al., 1985, 1990; Arnault and Roger, 1987; Volz et al., 1990; Turner and Herkenham, 1991; Yasui et al., 1991), as well as the temporal (auditory) cortex (Ryugo and Killackey, 1974; LeDoux et al., 1985; Arnault and Roger, 1987; Clerici and Coleman, 1990; Turner and Herkenham, 1991; Namura et al., 1997). A few observations have been made regarding projections from the posterior intralaminar nucleus to the ventromedial nucleus of the hypothalamus (LeDoux et al., 1984, 1985; Arnault and Roger, 1987) and the preoptic region (Simerly and Swanson, 1986; Coolen et al., 1998), without providing extensive data on the full pattern of efferent connections to other hypothalamic and forebrain areas. The results from our anterograde tracer deposits in the lateral parvicellular division of the subparafascicular and posterior intralaminar nuclei confirmed the reported projections to the amygdaloid complex, temporal cortex, ventromedial nucleus of the hypothalamus, and preoptic area and extended these findings by showing fibers and putative terminals in several additional areas, including many hypothalamic structures (the dorsomedial nucleus, the tuber cinereum area, the dorsal, anterior and lateral hypothalamic areas, the retrochiasmatic area, the medial and lateral preoptic area and lateral part of the medial preoptic nucleus, and the striohypothalamic nucleus), several subdivisions of the bed nucleus of the stria terminalis and substantia innominata, the lateral ventral and intermediate septal nuclei, and the horizontal limb of the diagonal band.

These results cannot easily be attributed to uptake of PHA-L/BDA to adjacent areas, such as dorsally in cells of the triangular posterior thalamic nucleus, which gave a very different pattern of labeling in the amygdala, in agreement with prior work from LeDoux and coworkers (1990), or ventrally by cells of the zona incerta or deep 
mesencephalic nuclei, which again produced a very different pattern of labeling excluding, for the most part, most of the hypothalamus and septum, with some labeling of the medial aspect of the central nucleus of the amygdala and lateral bed nucleus of the stria terminalis. Our results are relatively consistent with one case reported by Grove (1988; case RPPN6), in which an injection of PHA-L located more laterally in the posterior intralaminar nucleus and including part of the peripeduncular area also resulted in anterograde labeling in several areas of the hypothalamus, the bed nucleus of the stria terminalis, and the substantia innominata. (Observations in the septum were not reported.) Interestingly, however, that particular lateral injection produced much weaker labeling in all those areas, with few fibers and terminals in the paraventricular nucleus of the hypothalamus. These results are thus consistent with our observation of nearly exclusive FG labeling in the "medial" aspect of the posterior intralaminar nucleus adjacent to the parvicellular division of the subparafascicular nucleus of the hypothalamus. The use of the more sensitive PHA-L lectin and BDAs, compared with wheat germ agglutinin conjugated to horseradish peroxidase (WGA-HRP), might explain the more extensive projection fields reported in some (Grove, 1988; Coolen et al., 1998), but not other, studies focusing on efferent connections of the subparafascicular and posterior intralaminar nuclei.

\section{Comparisons with previous functional studies utilizing the immediate-early gene c-fos}

Several studies have reported the induction of immediate-early genes, particularly c-fos mRNA or its protein product Fos, in response to acute stressors (Sawchenko et al., 1996; Campeau et al., 1998). Particularly informative have been studies combining the use of retrograde tracer injections in the region of the PAmp with functional assays (invariably Fos), which have led to the delineation of probable circuits in the mediation of HPA axis activation following various acute challenges (Larsen and Mikkelsen, 1995; Cullinan et al., 1996; Li and Sawchenko, 1998). For instance, in response to an osmotic challenge induced by systemic injection of hypertonic saline (Larsen and Mikkelsen, 1995), the complement of regions displaying hyperosmotic Fos induction in PAmpprojecting neurons included several areas of the circumventricular organs (median preoptic nucleus, subfornical organ, and organum vasculosum lamina terminalis) implicated in the homeostatic control of osmosis, in addition to several areas known to respond to visceral inputs (nucleus of the solitary tract, ventrolateral medulla, and lateral parabrachial nucleus).

Not all these regions, however, appear to control activity of the HPA axis to the same extent, as only lesions of the organum vasculosum have been shown to block activating effects of hyperosmolality upon the parvocellular paraventricular nucleus (Kovacs and Sawchenko, 1993). A similar complement of brain regions is activated by immune challenges (Ericsson et al., 1994; Rivest and Rivier, 1994; Day and Akil, 1996), although with this particular stressor, inputs from the nucleus of the solitary tract and ventrolateral medulla have been implicated in providing excitatory effects at the level of the paraventricular nucleus (Li et al., 1996). The neural systems engaged by such systemic challenges, which require little conscious resources to be expressed, can be contrasted with the results obtained with the more "neurogenic" (Allen et al., 1973) or "processive" (Herman et al., 1996) challenges of swim (Cullinan et al., 1996), footshock ( $\mathrm{Li}$ and Sawchenko, 1998), and audiogenic stress (present study). For instance, in response to swim stress, Fos induction in PAmpprojecting neurons was observed in the parastrial nucleus, medial preoptic area, anterior and posterior hypothalamic areas, dorsomedial nucleus of the hypothalamus, and supramammillary nucleus. (Levels of the neuraxis rostral to the septum and caudal to the hypothalamus were not investigated in this study.)

A very similar forebrain pattern of Fos-immunoreactive PAmp-projecting neurons was reported following an acute footshock episode ( $\mathrm{Li}$ and Sawchenko, 1998), which is also remarkably comparable to the present observations following acute audiogenic stress. Notable differences seem to be related to the exact stressor employed. For instance, footshock does not appear to induce Fos in the PAmpprojecting neurons of the paratenial nucleus or the posterior thalamic nuclei, and audiogenic stress has not been observed to induce Fos in regions also known to project to the PAmp, including the lateral parabrachial nucleus and the ventrolateral periaqueductal gray (Campeau and Watson, 1997). These neurogenic stressors therefore appear to mediate control of the HPA axis via a much richer complement of forebrain structures compared with systemic stressors, while perhaps retaining some specificity provided by the exact stressor experienced (swim, electric shock, or loud noise). As with systemic stressors, the exact function of each of the activated PAmp-projecting areas needs to be ascertained to determine which input provides excitatory drive upon hypophysiotropic hypothalamic neurons in response to different neurogenic stressors.

\section{Putative functional circuits based on correlation of anterograde labeling from auditory-responsive areas of the thalamus and retrograde labeling from the paraventricular nucleus of the hypothalamus combined with Fos immunocytochemistry}

One way to help identify the putative functional circuits involved in activation of PAmp neurons by audiogenic stress is to correlate the results of the retrograde tracing from PAmp that were combined with Fos immunohistochemistry and the results of the anterograde tracing from the auditory-responsive posterior thalamic nuclei. The most likely circuits would be those for which there would be a relatively high number of retrogradely labeled neurons displaying Fos immunoreactivity that would appear to be contacted by a relatively large number of anterogradely labeled fibers and terminals. Among the areas displaying the highest correlation of Fos-positive retrogradely labeled neurons contacted by anterogradely labeled fibers, the parastrial hypothalamic nucleus, the anterior hypothalamic area, and the dorsomedial hypothalamic nucleus provide good candidates to relay auditory-related stress information to the PAmp (Fig. 6). Although the anterior nucleus of the paraventricular hypothalamic nucleus had a relatively high number of double-labeled cells, it received relatively few fibers and terminals from the auditory-responsive posterior thalamic 


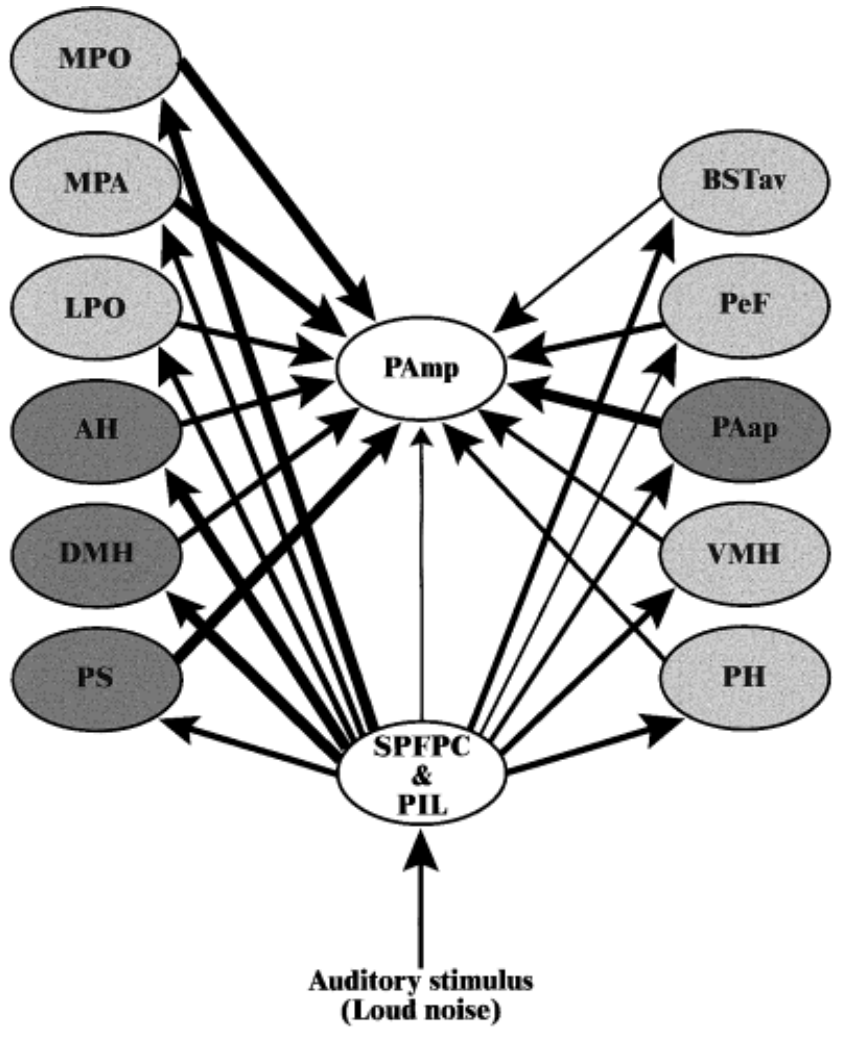

Fig. 6. Schematic diagram representing the relative strength of putative pathways involved in activation of secretory medial parvocellular paraventricular hypothalamic neurons by audiogenic stress. The thickness of the lines going from SPFPC \& PIL to other regions indicates the relative number of PHA-L fibers and putative terminals in each region. The thickness of the lines going from each region to the PAmp indicates the relative number of retrogradely labeled neurons in each region following Fluoro-Gold injection in the PAmp. The level of gray in each region indicates the relative number of cells observed to be double-labeled with Fos and Fluoro-Gold.

nuclei. The medial and lateral preoptic nuclei, medial preoptic area, posterior hypothalamus, perifornical nucleus, and ventromedial nucleus of the hypothalamus had moderate overlap between retrograde and anterograde labeling, suggesting their potential role in relaying auditory-related stress information to the PAmp. Other regions, including the anteroventral division of the bed nucleus of the stria terminalis, only had a few Fos-positive retrogradely labeled neurons, offering a possible but weak relay of auditory-related stress information to the PAmp. Finally, the lateral subparafascicular and posterior intralaminar nuclei also contained retrogradely labeled neurons, but few of them were Fos positive, suggesting a direct, although weak, auditory connection to the PAmp.

\section{Functional considerations}

Anatomically, the lateral parvicellular division of the subparafascicular nucleus and the posterior intralaminar nucleus share many characteristics; both receive auditory inputs from the inferior colliculus, visual inputs from the superior colliculus, and somatosensory inputs from the spinal cord (Ju et al., 1987; LeDoux et al., 1987; Nahin, 1988; Linke, 1999). A subset of their respective neurons contains at least one similar peptide, calcitonin-generelated peptide (Kubota et al., 1991; Yasui et al., 1991), and they have a similar projection pattern, including axon collaterals, to the amygdala and perirhinal cortex (Namura et al., 1997). The present results also suggest that these regions project directly to the parvocellular division of the paraventricular hypothalamic nucleus and to several additional forebrain areas of the hypothalamus and bed nucleus of the stria terminalis, seldom recognized in prior studies. Efferent projections from these thalamic areas contact several forebrain areas, which in turn project to PAmp, and some of them were shown to display Fos in response to audiogenic stress.

Together with our prior finding that auditory thalamic lesions, which included the posterior intralaminar nucleus and a large portions of the lateral parvicellular division of the subparafascicular nucleus, block audiogenic stressinduced glucocorticoid release and its associated forebrain c-fos mRNA induction (Campeau et al., 1997), the present results suggest that the lateral parvicellular division of the subparafascicular and posterior intralaminar nuclei might activate hypophysiotropic neurons of the paraventricular hypothalamic nucleus via either direct projections and/or indirect projections through one or several of the forebrain areas they contact. A functional analysis of these forebrain areas, including specific activation or inactivation, will be required to determine their exact role in HPA axis control. It has been demonstrated, for instance, that electrical stimulation of the anterolateral bed nucleus of the stria terminalis activates, whereas stimulation of its anteromedial subdivision inhibits, glucocorticoid release (Dunn, 1987). It should be noted that these areas need not be implicated uniquely in hypophysiotropic neuronal control or in responsiveness to auditory stimuli. For instance, a subset of the regions described above, namely, the parvicellular division of the subparafascicular nucleus and medial preoptic nucleus, has been implicated in the neural circuit of sexual satiety (Coolen et al., 1996, 1998). However, it has been reported that sexual behavior can produce the release of glucocorticoids (Szechtman et al., 1974; Bronson and Desjardins, 1982; Marchlewska-Koj and Sacharczuk-Kakietek, 1990), which potentially reinforces the role of these regions in the control of hypophysiotropic paraventricular neurons.

\section{CONCLUSIONS}

The results presented here indicate that some auditoryresponsive areas of the thalamus, including the lateral parvicellular region of the subparafascicular nucleus and the posterior intralaminar nucleus, project directly to corticotropin-releasing hormone-containing neurons of the paraventricular nucleus of the hypothalamus. In addition, it was observed that these same auditory-responsive posterior thalamic areas project to several forebrain areas also observed to contain retrogradely labeled neurons following Fluoro-Gold injections in the medial parvocellular region of the paraventricular hypothalamic nucleus. Together with our previous finding that auditory thalamic lesions disrupt corticosterone release in response to audiogenic stress, the present observations strongly suggest that these specific auditory-responsive posterior thalamic areas, (via either direct or, more likely, indirect projections to the paraventricular nucleus of the hypothalamus) mediate audiogenic stress-induced activation of hypophy- 
siotropic neurons of the paraventricular hypothalamic nucleus controlling the release of glucocorticoids.

\section{ACKNOWLEDGMENTS}

S.J.W. was the recipient of NIMH grant MH-42251, and S.C. received a Postdoctoral Fellowship from the Medical Research Council of Canada. Thanks are extended to Dr. Heidi E.W. Day for critical comments on an earlier draft of this manuscript.

\section{LITERATURE CITED}

Akil H, Morano M. 1995. Stress. In: Bloom F, Kupfer D, editors. Psychopharmacology: the fourth generation of progress. New York: Raven Press. p 773-785.

Akil H, Morano M. 1996. The biology of stress: from periphery to brain. In: Watson S, editor. Biology of schizophrenia and affective disease. Washington: American Psychiatric Press. p 15-48.

Allen JP, Allen CF, Greer MA, Jacobs JJ. 1973. Stress-induced secretion of ACTH. In: Brodish S, Redgate ES, editors. brain-pituitary-adrenal interrelationships. Basel: Karger. p 99-127.

Antoni FA. 1986. Hypothalamic control of adrenocorticotropin secretion: advances since the discovery of 41-residue corticotropin-releasing factor. Endocrine Rev 7:351-378.

Arnault P, Roger M. 1987. The connections of the peripeduncular area studied by retrograde and anterograde transport in the rat. J Comp Neurol 258:463-476.

Bittencourt J, Benoit R, Sawchenko P. 1991. Distribution and origins of substance P-immunoreactive projections to the paraventricular and supraoptic nuclei: partial overlap with ascending catecholaminergic projections. J Chem Neuroanat 4:63-78.

Bronson FH, Desjardins C. 1982. Endocrine responses to sexual arousal in male mice. Endocrinology 111:1286-1291.

Cameron AA, Khan IA, Westlund KN, Cliffer KD, Willis WD. 1995. The efferent projections of the periaqueductal gray in the rat: a Phasoleus vulgaris-leucoagglutinin study. I. Ascending projections. J Comp Neurol 351:568-584.

Campeau S, Watson SJ. 1997. Neuroendocrine and behavioral responses and brain pattern of c-fos induction associated with audiogenic stress. J Neuroendocrinol 9:577-588.

Campeau S, Akil H, Watson SJ. 1997. Lesions of the medial geniculate nuclei specifically block corticosterone release and induction of c-fos mRNA in the forebrain associated with loud noise stress in rats. J Neurosci 17:5979-5992.

Campeau S, Day HEW, Helmreich DL, Kollack-Walker S, Watson SJ. 1998. Principles of psychoneuroendocrinology. In: Nemeroff CB, editor. Clinics of psychiatry: psychoneuroendocrinology. Philadelphia: WB Saunders. p 1-18.

Canteras NS, Swanson LW. 1992. Projections of the ventral subiculum to the amygdala, septum, and hypothalamus: a PHAL anterograde tracttracing study in the rat. J Comp Neurol 324:180-194.

Canteras NS, Simerly RB, Swanson LW. 1995. Organization of projections from the medial nucleus of the amygdala: a PHAL study in the rat. J Comp Neurol 360:213-245.

Cheung S, Ballew JR, Moore KE, Lookingland KJ. 1998. Contribution of dopamine neurons in the medial zona incerta to the innervation of the central nucleus of the amygdala, horizontal diagonal band of Broca and hypothalamic paraventricular nucleus. Brain Res 808:174-181.

Clerici WJ, Coleman JR. 1990. Anatomy of the rat medial geniculate body: I. Cytoarchitecture, myeloarchitecture, and neocortical connectivity. J Comp Neurol 297:14-31.

Coolen LM, Peters HJPW, Veening JG. 1996. Fos-immunoreactivity in the rat brain following consummatory elements of sexual behavior: a sex comparison. Brain Res 738:67-82.

Coolen LM, Peters HJPW, Veening JG. 1998. Anatomical interrelationships of the medial preoptic area and other brain regions activated following male sexual behavior: a combined Fos and tract-tracing study. J Comp Neurol 397:421-435.

Cullinan WE, Herman JP, Watson SJ. 1993. Ventral subicular interaction with the hypothalamic paraventricular nucleus: evidence for a relay in the bed nucleus of the stria terminalis. J Comp Neurol 332:1-20.

Cullinan WE, Helmreich DL, Watson SJ. 1996. Fos expression in forebrain afferents to the hypothalamic paraventricular nucleus following swim stress. J Comp Neurol 368:88-99.

Day HEW, Akil H. 1996. Differential pattern of c-fos mRNA in rat brain following central and systemic administration of interleukin-1-beta: implications for mechanism of action. Neuroendocrinology 63:207-218.

Dunn JD. 1987. Plasma corticosterone responses to electrical stimulation of the bed nucleus of the stria terminalis. Brain Res 407:327-331.

Ericsson A, Kovacs KJ, Sawchenko PE. 1994. A functional anatomical analysis of central pathways subserving the effects of interleukin-1 on stress-related neuroendocrine neurons. J Neurosci 14:897-913.

Floyd NS, Keay KA, Arias CM, Sawchenko PE, Bandler R. 1996. Projections from the ventrolateral periaqueductal gray to endocrine regulatory subdivisions of the paraventricular nucleus of the hypothalamus in the rat. Neurosci Lett 220:105-108.

Gray TS, Carney ME, Magnuson DJ. 1989. Direct projections from the central amygdaloid nucleus to the hypothalamic paraventricular nucleus: possible role in stress-induced adrenocortocotropin release. Neuroendocrinology 50:433-446.

Grove EA. 1988. Neural associations of the substantia innominata in the rat: Afferent connections. J Comp Neurol 277:315-346.

Herman JP, Cullinan WE. 1997. Neurocircuitry of stress: central control of the hypothalamo-pituitary-adrenocortical axis. Trends Neurosci 20: $78-84$.

Herman JP, Prewitt CM-F, Cullinan WE. 1996. Neuronal circuit regulation of the hypothalamo-pituitary-adrenocortical stress axis. Crit Rev Neurobiol 10:371-394.

Horvath TL. 1998. An alternate pathway for visual signal integration into the hypothalamo-pituitary axis: retinorecipient intergeniculate neurons project to various regions of the hypothalamus and innervate neuroendocrine cells including those producing dopamine. J Neurosci 18:1546-1558

Ju G, Melander T, Ceccatelli S, Hokfelt T, Frey P. 1987. Immunohistochemical evidence for a spinothalamic pathway co-containing cholecystokinin- and galanin-like immunoreactivities in the rat. Neuroscience 20:439-456

Kohler C. 1990. Subicular projections to the hypothalamus and brainstem: some novel aspects revealed in the rat by the anterograde Phaseolus vulgaris leucoagglutinin (PHA-L) tracing method. Prog Brain Res 83: 59-69.

Kovacs KJ, Sawchenko PE. 1993. Mediation of osmoregulatory influences on neuroendocrine corticotropin-releasing factor expression in the ventral lamina terminalis. Proc Natl Acad Sci USA 90:7681-7685.

Kubota Y, Inagaki S, Shimada S, Takatsuji K, Tohyama M, Takagi H. 1991. Striatal calcitonin gene-related peptide-like immunoreactive afferents from the regions ventral and medial to the medial geniculate nucleus of rats. Neuroscience 40:423-428.

Larsen PJ, Hay-Schmidt A, Mikkelsen JD. 1994. Efferent connections from the lateral hypothalamic region and lateral preoptic area to the hypothalamic paraventricular nucleus of the rat. J Comp Neurol 342:299319.

Larsen P, Mikkelsen J. 1995. Functional identification of central afferent projections conveying information of acute "stress" to the hypothalamic paraventricular nucleus. J Neurosci 15:2609-2627.

LeDoux JE, Sakaguchi A, Reis DJ. 1984. Subcortical efferent projections of the medial geniculate nucleus mediate emotional responses conditioned to acoustic stimuli. J Neurosci 4:683-698.

LeDoux JE, Ruggiero DA, Reis DJ. 1985. Projections to the subcortical forebrain from anatomically defined regions of the medial geniculate body in the rat. J Comp Neurol 242:182-213.

LeDoux JE, Ruggiero DA, Forest R, Stornetta R, Reis DJ. 1987. Topographic organization of convergent projections to the thalamus from the inferior colliculus and spinal cord in the rat. J Comp Neurol 264: 123-146.

LeDoux JE, Farb C, Ruggiero DA. 1990. Topographic organization of neurons in the acoustic thalamus that project to the amygdala. J Neurosci 10:1043-1054.

Levin MC, Sawchenko PE, Howe PRC, Bloom SR, Polak JM. 1987. Organization of galanin-immunoreactive inputs to the paraventricular nucleus with special reference to their relationship to catecholaminergic afferents. J Comp Neurol 261:562-582.

Levine S, Ursin H. 1991. What is stress? In: Brown MR, Koob GF, Rivier C, editors. Stress: neurobiology and neuroendocrinology. New York: Marcel Dekker. p 3-21.

Li HY, Sawchenko PE. 1998. Hypothalamic effector neurons and extended circuitries activated in "neurogenic" stress: a comparison of footshock 
effects exerted acutely, chronically, and in animals with controlled glucocorticoid levels. J Comp Neurol 393:244-266.

Li H-Y, Ericsson A, Sawchenko PE. 1996. Distinct mechanisms underlie activation of hypothalamic neurosecretory neurons and their medullary catecholaminergic afferents in categorically different stress paradigms. Proc Natl Acad Sci USA 93:2359-2364.

Linke R. 1999. Differential projection patterns of superior and inferior collicular neurons onto posterior paralaminar nuclei of the thalamus surrounding the medial geniculate body in the rat. Eur J Neurosci 11:187-203.

Marchlewska-Koj A, Sacharczuk-Kakietek M. 1990. Acute increase in plasma corticosterone level in female mice evoked by pheromones. Physiol Behav 48:577-580.

Marcilhac A, Siaud P. 1997. Identification of projections from the central nucleus of the amygdala to the paraventricular nucleus of the hypothalamus which are immunoreactive for corticotrophin-releasing hormone in the rat. Exp Physiol 82:273-281.

Moga M, Saper C. 1994. Neuropeptide-immunoreactive neurons projecting to the paraventricular hypothalamic nucleus in the rat. J Comp Neurol 346:137-150.

Moga MM, Weis RP, Moore RY. 1995. Efferent projections of the paraventricular thalamic nucleus in the rat. J Comp Neurol 359:221-238.

Nahin RL. 1988. Immunocytochemical identification of long ascending, peptidergic lumbar spinal neurons terminating in either the medial or lateral thalamus in the rat. Brain Res 443:345-349.

Namura S, Takada M, Kikuchi H, Mizuno N. 1997. Collateral projections of single neurons in the posterior thalamic region to both the temporal cortex and the amygdala: a fluorescent retrograde double-labeling study in the rat. J Comp Neurol 384:59-70.

Oldfield BJ, Silverman A-J. 1985. A light microscopic HRP study of limbic projections to the vasopressin-containing nuclear groups of the hypothalamus. Brain Res Bull 14:143-157.

Ottersen OP. 1981. Afferent connections to the amygdaloid complex of the rat with some observations in the cat. III. Afferents from the lower brain stem. J Comp Neurol 202:335-356.

Ottersen OP, Ben-Ari Y. 1979. Afferent connections to the amygdaloid complex of the rat and cat. J Comp Neurol 1979:401-424.

Paxinos G, Watson C. 1998. The rat brain in stereotaxic coordinates, 4th ed. San Diego, CA: Academic Press.

Prewitt CMF, Herman JP. 1998. Anatomical interactions between the central amygdaloid nucleus and the hypothalamic paraventricular nucleus of the rat: a dual tract-tracing analysis. J Chem Neuroanat 15:173-185.

Rivest S, Rivier C. 1994. Stress and interleukin-1 $\beta$-induced activation of c-fos, NGFI-B and CRF gene expression in the hypothalamic PVN: comparison between Sprague-Dawley, Fisher-344 and Lewis rats. J Neuroendocrinol 6:101-117.

Roland BI, Sawchenko PE. 1993. Local origins of some GABAergic projections to the paraventricular and supraoptic nuclei of the hypothalamus in the rat. J Comp Neurol 332:123-143.

Ryugo DK, Killackey HP. 1974. Differential telencephalic projections of the medial and ventral divisions of the medial geniculate body of the rat. Brain Res 82:173-177.

Sawchenko PE. 1991. The final common path: issues concerning the organization of central mechanisms controlling corticotropin secretion. In: Brown M, Koob G, Rivier C, editors. Stress neurobiology and neuroendocrinology. New York: Marcel Dekker. p 55-71.
Sawchenko PE, Swanson LW. 1982. The organization of noradrenergic pathways from the brainstem to the paraventricular and supraoptic nuclei in the rat. Brain Res Brain Res Rev 4:275-325.

Sawchenko PE, Swanson LW. 1983. The organization of the forebrain afferents to the paraventricular and supraoptic nuclei. J Comp Neurol 218:121-144.

Sawchenko PE, Brown ER, Chan RKW, Ericsson A, Li H-Y, Roland BL, Kovacs KJ. 1996. The paraventricular nucleus of the hypothalamus and the functional neuroanatomy of visceromotor responses to stress. In: Holstege G, Bandler R, Saper CB, editors. Progress in brain research, vol 107. The emotional motor system. Amsterdam: Elsevier. p 201-222.

Silverman AJ, Hoffman DL, Zimmerman EA. 1981. The descending afferent connections of the paraventricular nucleus of the hypothalamus. Brain Res Bull 6:47-61.

Simerly RB, Swanson LW. 1986. The organization of neural inputs to the medial preoptic nucleus of the rat. J Comp Neurol 246:312-342.

Simerly RB, Swanson LW. 1988. Projections of the medial preoptic nucleus: a Phaseolus vulgaris leucoagglutinin anterograde tract-tracing study in the rat. J Comp Neurol 270:209-242.

Staiger JF, Wouterlood FG. 1990. Efferent projections from the lateral septal nucleus to the anterior hypothalamus in the rat: a study combining Phaseolus vulgaris-leucoagglutinin tracing with vasopressin immunocytochemistry. Cell Tissue Res 261:17-23.

Swanson LW, Sawchenko PE, Lind RW, Rho J-H. 1988. The CRH motoneuron: differential peptide regulation in neurons with possible synaptic, paracrine and endocrine outputs. Ann N Y Acad Sci 512:12-23.

Szechtman H, Lambrou PJ, Caggiula AR, Redgate ES. 1974. Plasma corticosterone levels during sexual behavior in male rats. Horm Behav 5:191-200.

Toates F. 1995. Stress. Conceptual and biological aspects. Chichester: John Wiley \& Sons.

Tribollet E, Dreifuss JJ. 1981. Localization of neurones projection to the hypothalamic paraventricular nucleus area of the rat: a horseradish peroxidase study. Neuroscience 6:1315-1328.

Turner B, Herkenham M. 1981. An autoradiographic study of thalamoamygdaloid connections in the rat. Anat Rec 199:260A.

Turner BH, Herkenham M. 1991. Thalamoamygdaloid projections in the rat: a test of the amygdala's role in sensory processing. J Comp Neurol 313:295-325.

Ursin H, Olff M. 1993. The stress response. In: Stanford SC, Salmon P, editors. Stress: from synapse to syndrome. San Diego: Academic Press. p 3-22.

Veening JG. 1978. Subcortical afferents of the amygdaloid complex in the rat: an HRP study. Neurosci Lett 8:197-202.

Volz H-P, Rehbein G, Triepel J, Knuepfer MM, Stumpf H, Stock G. 1990. Afferent connections of the nucleus centralis amygdalae. Anat Embryol 181:177-194.

Wagner CK, Eaton MJ, Moore KE, Lookingland KJ. 1995. Efferent projections from the region of the medial zona incerta containing A13 dopaminergic neurons: a PHA-L anterograde tract-tracing study in the rat. Brain Res 677:229-237.

Yasui Y, Saper CB, Cechetto DF. 1991. Calcitonin gene-related peptide (CGRP) immunoreactive projections from the thalamus to the striatum and amygdala in the rat. J Comp Neurol 308:293-310.

Yehuda R. 1997. Stress and glucocorticoid. Science 275:1662-1663. 